\title{
DRIFTS band areas as measured pool size proxy to reduce parameter uncertainty in soil organic matter models
}

\author{
Moritz Laub $^{1}$, Michael Scott Demyan ${ }^{2}$, Yvonne Funkuin Nkwain ${ }^{1}$, Sergey Blagodatsky ${ }^{1,3}$, Thomas Kätterer ${ }^{4}$, \\ Hans-Peter Piepho ${ }^{5}$, and Georg Cadisch ${ }^{1}$ \\ ${ }^{1}$ Institute of Agricultural Sciences in the Tropics (Hans-Ruthenberg-Institute), \\ University of Hohenheim, Garbenstrasse 13, 70599 Stuttgart, Germany \\ ${ }^{2}$ School of Environment and Natural Resources, The Ohio State University, \\ 2021 Coffey Rd., Columbus, OH 43210, USA, \\ ${ }^{3}$ Institute of Physicochemical and Biological Problems in Soil Science, \\ Russian Academy of Sciences, 142290 Pushchino, Russia \\ ${ }^{4}$ Department of Ecology, Swedish University of Agricultural Sciences, Ulls Väg 16, Uppsala, Sweden \\ ${ }^{5}$ Biostatistics Unit, Institute of Crop Science, University of Hohenheim, Fruwirthstr. 23, 70599 Stuttgart, Germany
}

Correspondence: Moritz Laub (moritz.laub@uni-hohenheim.de) and Georg Cadisch (georg.cadisch@uni-hohenheim.de)

Received: 25 July 2019 - Discussion started: 7 August 2019

Revised: 11 February 2020 - Accepted: 13 February 2020 - Published: 20 March 2020

\begin{abstract}
Soil organic matter (SOM) turnover models predict changes in SOM due to management and environmental factors. Their initialization remains challenging as partitioning of SOM into different hypothetical pools is intrinsically linked to model assumptions. Diffuse reflectance mid-infrared Fourier transform spectroscopy (DRIFTS) provides information on SOM quality and could yield a measurable pool-partitioning proxy for SOM. This study tested DRIFTS-derived SOM pool partitioning using the Daisy model. The DRIFTS stability index (DSI) of bulk soil samples was defined as the ratio of the area below the aliphatic absorption band $\left(2930 \mathrm{~cm}^{-1}\right)$ to the area below the aromaticcarboxylate absorption band $\left(1620 \mathrm{~cm}^{-1}\right)$. For pool partitioning, the DSI $\left(2930 \mathrm{~cm}^{-1} / 1620 \mathrm{~cm}^{-1}\right)$ was set equal to the ratio of fast-cycling / slow-cycling SOM. Performance was tested by simulating long-term bare fallow plots from the Bad Lauchstädt extreme farmyard manure experiment in Germany (Chernozem, 25 years), the Ultuna continuous soil organic matter field experiment in Sweden (Cambisol, 50 years), and 7 year duration bare fallow plots from the Kraichgau and Swabian Jura regions in southwest Germany (Luvisols). All experiments were at sites that were agricultural fields for centuries before fallow establishment, so classical theory would suggest that a steady state can be assumed for initializing SOM pools. Hence, steady-state and
\end{abstract}

DSI initializations were compared, using two published parameter sets that differed in turnover rates and humification efficiency. Initialization using the DSI significantly reduced Daisy model error for total soil organic carbon and microbial carbon in cases where assuming a steady state had poor model performance. This was irrespective of the parameter set, but faster turnover performed better for all sites except for Bad Lauchstädt. These results suggest that soils, although under long-term agricultural use, were not necessarily at a steady state. In a next step, Bayesian-calibrationinferred best-fitting turnover rates for Daisy using the DSI were evaluated for each individual site or for all sites combined. Two approaches significantly reduced parameter uncertainty and equifinality in Bayesian calibrations: (1) adding physicochemical meaning with the DSI (for humification efficiency and slow SOM turnover) and (2) combining all sites (for all parameters). Individual-site-derived turnover rates were strongly site specific. The Bayesian calibration combining all sites suggested a potential for rapid SOM loss with $95 \%$ credibility intervals for the slow SOM pools' halflife being 278 to 1095 years (highest probability density at 426 years). The credibility intervals of this study were consistent with several recently published Bayesian calibrations of similar two-pool SOM models, i.e., with turnover rates 
being faster than earlier model calibrations suggested; hence they likely underestimated potential SOM losses.

\section{Introduction}

Process-based models of plant-soil ecosystems are used from plot to global scales as tools of research and to support policy decisions (Campbell and Paustian, 2015). In soil organic matter (SOM) models, SOM is traditionally divided into several pools, representing fast- and slow-cycling or even inert SOM (Hansen et al., 1993; Parton et al., 1993). However, these theoretical SOM pools cannot easily be linked to measurable fractions. As a workaround, common methods of SOM pool initialization require that one assumes SOM at a steady state or includes a model spin-up run, attempting to simulate SOM dynamics according to history and carbon inputs for the decades to several millennia prior to the period of actual interest (e.g., O'Leary et al., 2016). Theoretically if SOM pools are at a steady state and turnover times of SOM pools are known, models could be initialized, i.e., pool sizes calculated, either by simple equations (e.g., for Daisy, Bruun and Jensen, 2002) or by inverse modeling (for RothC, Coleman and Jenkinson, 1996). In most cases, data are insufficient to guarantee that the assumptions of a SOM steady state or long-term land use history and inputs are correct, given the lack of data on residue and manure input and weather variability on the required long-term timescales (>200 years to millennia). Furthermore, exact turnover times of different SOM pools are unknown, which makes the results of inverse modeling and steady-state initializations a direct result of model assumptions (Bruun and Jensen, 2002). Hence, it is critical to find measurable proxies, such as soil size density fractionation or infrared spectra (Sohi et al., 2001), that can provide information on the quality of SOM and help to disconnect the intrinsic link between turnover times and SOM pool division for SOM pool initialization.

As was shown by Zimmermann et al. (2007), and recently confirmed by Herbst et al. (2018), a link exists between soil fractions obtained by size and density fractionation and fastand slow-cycling SOM pools. However, Poeplau et al. (2013) showed that the same fractionation protocol led to considerably different results in six different laboratories which regularly applied the technique (coefficient of variation from $14 \%$ to $138 \%$ ). The resulting differences in the model initializations for simulated SOM loss after 40 years of fallow, led to differences in SOM losses that were to up to $30 \%$ of initial SOM. Hence there is a need for a reproducible proxy for SOM pool initialization to reduce the high uncertainty in SOM models. We hypothesized that such a proxy could be obtained from inexpensive, high-throughput diffuse reflectance mid-infrared Fourier transform spectroscopy (DRIFTS).
As a novel approach, this study uses information gained from DRIFTS spectra to partition measured SOM into pools of different complexity. DRIFTS can provide information on SOM quality but also on texture and even mineralogy (Nocita et al., 2015; Tinti et al., 2015). The absorbance of mid-infrared light by molecular bonds in the soil sample vibrating at the same frequency produces typical absorption bands at distinct wavelengths (Stevenson, 1994). The area below absorption bands (in short, band area), can be linked to different molecular bonds of carbohydrates, amides, silicates and others. Two important absorption bands that provide information on SOM quality are the aliphatic carbon band $\left(2930 \mathrm{~cm}^{-1}\right.$; limits, $\left.3010-2800 \mathrm{~cm}^{-1}\right)$ and the aromaticcarboxylate band $\left(1620 \mathrm{~cm}^{-1}\right.$; limits, $1660-1580 \mathrm{~cm}^{-1}$; Giacometti et al., 2013; Margenot et al., 2015; Pengerud et al., 2013). While both bands are subject to interference $\left(2930 \mathrm{~cm}^{-1}\right.$ mainly from water and $1620 \mathrm{~cm}^{-1}$ mainly from minerals; Nguyen et al., 1991), it should be possible to limit the interference using subregions of the absorption bands with carefully selected integration limits. Indeed, Demyan et al. (2012) found aliphatic carbon to be enriched under longterm farmyard manure application and depleted in mineral fertilizer or control treatments and showed that the ratio of the 1620 to $2930 \mathrm{~cm}^{-1}$ band area had a significant positive correlation with the ratio of stable to labile SOM obtained by size and density fractionation. It was further corroborated that the band areas they used, which mainly selected the top subregion of the absorption bands, are strongly reduced or lost during combustion (Demyan et al., 2013). Hence, we hypothesized that the ratio of areas below aliphatic to aromaticcarboxylate carbon absorption bands can be used as proxy for the ratio of fast- to slow-cycling SOM for pool initialization, thus providing a major improvement over assuming steadystate SOM. The ratio of areas below absorbance bands of aliphatic to aromatic-carboxylate carbon will be referred to as the DRIFTS stability index (DSI) hereafter. Testing, improvement and proper use of the DSI were the central topics of this study. Recent findings have highlighted that the residual water content in bulk soil samples after drying at different temperatures affects the DSI considerably. Water absorbance affects significant parts of the mid-infrared spectra and particularly influences the 2930 and $1620 \mathrm{~cm}^{-1}$ band areas (Laub et al., 2019). For this reason, we also tested how the drying temperature prior to DRIFTS measurements affects the use of the DSI proxy, using 32,65 and $105^{\circ} \mathrm{C}$ as pretreatment temperatures.

To test our hypotheses about DSI performance, we used the Daisy SOM model (Hansen et al., 2012). Daisy is a commonly used SOM model (Campbell and Paustian, 2015) with a typical multipool structure, which includes two soil microbial biomass (SMB) pools as well as two pools for stabilized SOM (fast and slow cycling). With first-order turnover kinetics and a humification efficiency parameter (Fig. 1), the Daisy structure is similar to other widely used SOM models such as CENTURY (Parton et al., 1993) or ICBM (Andrén 
and Kätterer, 1997). Model SOM pool initialization using the DSI was compared to initialization via a steady-state assumption with different published turnover rates. For this comparison bare fallow experiments from a range of different sites and over timescales of 1 to 5 decades were included. Bare fallow experiments were used to avoid the added complexity caused by the conversion of different plant compounds into SOM of varying stabilities during decomposition.

As SOM pool sizes and turnover rates are closely linked, it could also be necessary to recalibrate Daisy parameters for the use of the DSI. Therefore, a Bayesian calibration of turnover rates was used to adjust Daisy turnover rates to the pool division and time dynamics of the measured DSI throughout the fallow period. Thus, the Daisy parameterization was evaluated with respect to equifinality and uncertainty as well as to dependence on model structure. The final hypothesis was that, through a Bayesian calibration using the DSI, Daisy pools will correspond to measured, i.e., physiochemically meaningful, fractions, thus reducing uncertainty. The posterior credibility intervals and optima of turnover rates should correspond to the results of other Bayesian calibrations carried out for similarly structured two-pool models. If such relations could be confirmed, this would point towards fundamental insights about the intrinsic SOM turnover in temperate agroecosystems.

\section{Material and methods}

\subsection{Study sites and data used for modeling}

Datasets originating from bare fallow treatments of four different sites with different experimental durations and measurement frequencies were used in this study. Topsoil (0$20 \mathrm{~cm}$ ) samples were received from the long-term experiments of (a) the Ultuna continuous soil organic matter field experiment (established in 1956, with additional samples from 1979, 1995 and 2005 taken in autumn (Kätterer et al., 2011), four replicates) and (b) the Bad Lauchstädt extreme farmyard manure experiment (established in 1983, with additional samples from 2001, 2004 and 2008 taken in autumn (Blair et al., 2006), two replicates; https://www.ufz.de/index. php?de=37008, last access: 10 January 2019). Additional data from two medium-term bare fallow experiments (established in autumn 2009 with data until 2016) from southwest German regions were included. In these experiments three fields in the region of (c) the Kraichgau and three fields in the region of (d) the Swabian Jura, representing different climatic and geological conditions, were intensely monitored. The bare fallow plots $(5 \mathrm{~m} \times 5 \mathrm{~m}$ size $)$ in these experiments were established within agricultural fields with three replicates per field (Ali et al., 2015). Up to four topsoil samples $(0-30 \mathrm{~cm})$ were taken throughout the year. Further details on all the sites can be found in Table 1 . All sites had been under cultivation for at least several hundred years prior to es- tablishing the bare fallow plots, which would suggest that a steady state could be assumed.

All available bulk soil samples of Ultuna and Bad Lauchstädt were analyzed for total organic carbon and DRIFTS spectra. For the Kraichgau and Swabian Jura sites, total organic carbon and DRIFTS spectra were measured about once every 2 years, while soil microbial biomass carbon (SMBC) was measured up to four times per year. All bulk soil samples (except for SMB-C) were passed through a $2 \mathrm{~mm}$ sieve, then air-dried, ball-milled (for $2 \mathrm{~min}$ ) to powder and stored until further analysis was carried out. Soil organic carbon (SOC) content was analyzed with a vario MAX CNS (Elementar Analysensysteme GmbH, Hanau, Germany). Soil samples for DRIFTS analysis were obtained after $24 \mathrm{~h}$ of drying at 32,65 and $105^{\circ} \mathrm{C}$. The dried samples were kept in a desiccator until measurement. DRIFTS spectra of bulk soil samples (with four subsamples per sample) were obtained using an HTS-XT microplate extension, mounted to a TENSOR 27 spectrometer using the processing software OPUS 7.5 (Bruker Optik GmbH, Ettlingen, Germany). A potassium bromide $(\mathrm{KBr})$ beam splitter with a nitrogen-cooled HTS$\mathrm{XT}$ reflection detector was used to record spectra in the midinfrared range $\left(4000-400 \mathrm{~cm}^{-1}\right)$. Each spectrum was a combination of 16 coadded scans with a $4 \mathrm{~cm}^{-1}$ resolution. Spectra were recorded and then converted to absorbance units (AU); the acquisition mode double-sided, forward-backward and the apodization function Blackman-Harris 3 were used. After baseline correction and vector normalization of the spectra, areas below absorptions bands of interest were obtained by integration using a local baseline with the integration limits of Demyan et al. (2012). Integrated band areas of the four subsamples were then averaged. The local baselines were drawn between the intersection of the spectra and a vertical line at the integration limits $\left(3010-2800 \mathrm{~cm}^{-1}\right.$ for the aliphatic carbon band, $1660-1580 \mathrm{~cm}^{-1}$ for the aromaticcarboxylate carbon band). Example spectra and integrated band areas are displayed in Fig. S1 in the Supplement. The integration limits were selected with the goal of reducing signal interference from water and minerals, using spectra of pure substances, clay minerals and DRIFTS spectra gained during heating samples up to $700{ }^{\circ} \mathrm{C}$ (Demyan et al., 2013). Particularly, the mineral interference close to the $1620 \mathrm{~cm}^{-1}$ band makes accurate selection of integration limits necessary so that only its top part (assumed to consist mostly of aromatic-carboxylate carbon) is selected. In the case of our samples, the selected specific band area of the $1620 \mathrm{~cm}^{-1}$ band accounted for approximately $10 \%$ to $30 \%$ of the band area of the larger surrounding band (Fig. S1, ca. 1755$1555 \mathrm{~cm}^{-1}$ ). Integration limits were chosen so that the band area best corresponds to the portion that is lost with combustion or chemical oxidation (Demyan et al., 2013; Yeasmin et al., 2017). A strong correlation between the DSI and the percentage of centennially persistent SOC $(r=0.84)$ from the combined long-term experiments used in this study (using values of centennially persistent SOC from Cécillon et 


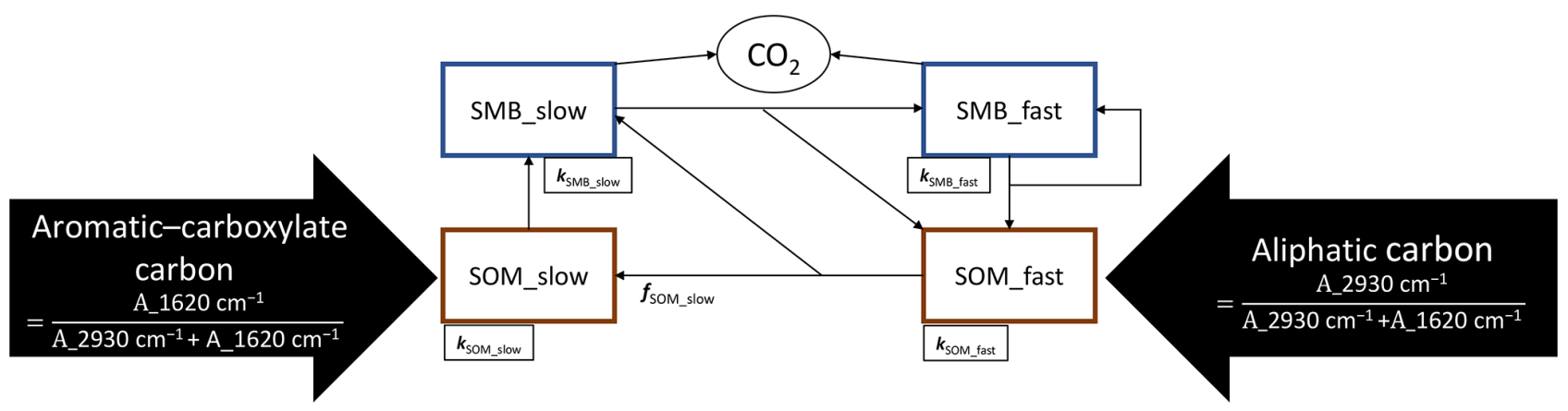

Figure 1. Original structure of the internal cycling of SOM in the Daisy model, as it was used in this study. A_2930 $\mathrm{cm}^{-1}$ and A_1620 $\mathrm{cm}^{-1}$ refer to the areas below the DRIFTS absorption bands at $2930 \mathrm{~cm}^{-1}$ and $1620 \mathrm{~cm}^{-1}$ (Eq. 3); $k_{\mathrm{SOM}}$ and $k_{\mathrm{SOM}}$ (fast and slow) are turnover rates of the fast and slow SOM and SMB pools, respectively, and $f_{\mathrm{SOM} \text { slow }}$ is the humification efficiency. All model parameters can be found in Table 2 .

al., 2018; Franko and Merbach, 2017) showed that the DSI selected in this manner did in fact explain a large portion of the SOC quality change across sites (Fig. S2).

Additionally, soils from the experiments in Kraichgau and Swabian Jura were analyzed for SMB-C using the chloroform fumigation extraction method (Joergensen and Mueller, 1996). Briefly, field-moist samples were transported to the lab in a cooler, with extractions beginning within $24 \mathrm{~h}$ of field sampling and the final SMB-C values corrected to an ovendried $\left(105^{\circ} \mathrm{C}\right)$ basis. The SMB-C was measured two to four times throughout the whole year. Stocks of SOC and SMB-C for $0-30 \mathrm{~cm}$ were calculated by multiplying the percentage of SOC and SMB-C with the bulk density and sampled layer thickness (Table 1), respectively. Bulk density was assumed constant for Bad Lauchstädt, Kraichgau and Swabian Jura, while for Ultuna the initial $1.44 \mathrm{Mg} \mathrm{m}^{-3}$ (Kirchmann et al., 2004) in the beginning was used for all but the last measurement, where $1.43 \mathrm{Mg} \mathrm{m}^{-3}$ (Kätterer et al., 2011) was used. Due to low coarse-fragment contents $(<5 \%$ for Swabian Jura $3,<2 \%$ for Swabian Jura 1 and $<1 \%$ for the other six sites), and because changes in stone content throughout the simulation periods are unlikely, no correction for coarsefragment content was done.

\subsection{Description of the simulation model Daisy Expert-N 5.0}

All simulations were conducted using the Daisy SOM model (Hansen et al., 2012) integrated into the Expert-N 5.0 modeling framework. Expert-N 5.0 allows for a wide range of soil, plant and water models to be combined and interchanged (Heinlein et al., 2017; Klein et al., 2017; Klein, 2018). Expert-N can be compiled for both Windows and Linux systems. The Daisy model consists of two pools (fast and slow cycling) for each of the measurable fractions of (1) litter, (2) SMB and (3) stabilized SOM (Fig. 1). Due to bare fallow, litter pools were disregarded in this study, and the focus was on initializing the two SOM pools. A detailed descrip- tion of the Daisy SOM submodule as it was implemented into the Expert-N 5.0 framework can be found in Mueller et al. (1997). The additional modules available for selection in the Expert-N 5.0 framework consist of a selection of established models for all simulated processes in the soilplant continuum. The evaporation, ground heat, net radiation and emissivity were simulated according to the PenmanMonteith equation (Monteith, 1976). Water flow through the soil profile was simulated by the HYDRUS flow module (van Genuchten, 1982) with the hydraulic functions according to Mualem (1976). Heat transfer through the soil profile was simulated with the Daisy heat module (Hansen et al., 1993). In the first step of the DSI evaluation, simulations were conducted with two established parameter sets for Daisy SOM. The first set was from Mueller et al. (1997) and was a modification of the original parameter set of turnover rates reported by Jensen et al. (1997). The second set was established after calibrations made by Bruun et al. (2003) using the Askov long-term experiments, in which they introduced considerable changes to the turnover rates of the slow SOM pool and the humification efficiency. An equation developed by Bruun and Jensen (2002) was used to compute the proportions of the slow- and fast-cycling SOM pools for both parameter sets at a steady state (see next section). Parameters of both sets are given in Table 2.

For simulating soil temperature and moisture in Expert-N, daily averages of radiation, temperature, precipitation, relative humidity and wind speed are needed. For the longterm experiments they were extracted from the nearest weather station with complete data (Ultuna source specifications are as follows: Swedish Agricultural University; European Climate Assessment station ID 5506; elevation $15 \mathrm{~m} ; 59.8100^{\circ} \mathrm{N}, 17.6500^{\circ} \mathrm{E}$. Bad Lauchstädt specifications are as follows: Deutscher Wetterdienst Station 2932; elevation $131 \mathrm{~m} ; 51.4348^{\circ} \mathrm{N}, 12.2396^{\circ} \mathrm{E}$; locality name, LeipzigHalle). For the fields of the Kraichgau and Swabian Jura, the driving variables were measured by weather stations installed next to eddy covariance stations located at the cen- 


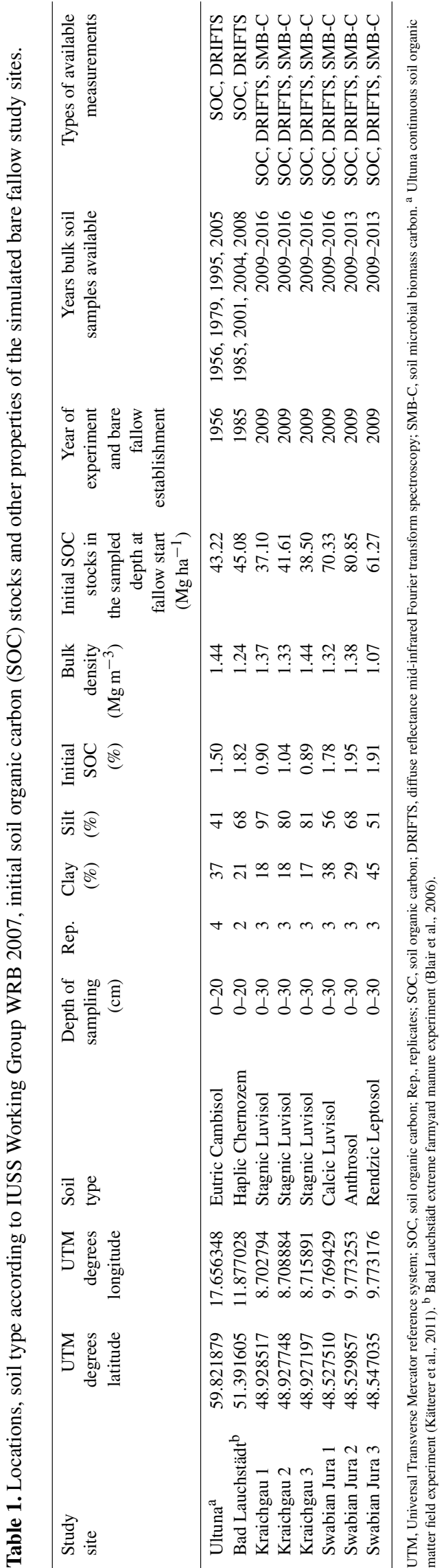

ter of each field. Details on the measurements and instrumentation as well as the gap-filling methods of those eddy covariance weather stations are described in Wizemann et al. (2015).

\subsection{SOM pool initializations with the DRIFTS stability index and at a steady state}

Measured bulk soil SOC includes SMB-C; therefore the amount of SOC in the fast- and slow-cycling SOM pools combined consists of bulk soil SOC minus measured SMBC. Partitioning of measured SMB-C into slow-cycling ( $90 \%)$ and fast-cycling $(10 \%)$ microbial pools was carried out similarly to Mueller et al. (1998).

The remaining carbon (difference between bulk soil SOC and SMB-C) was divided between fast- and slow-cycling SOM pools either by the DRIFTS stability index (DSI) or according to the steady-state assumption. For steady-state division, the equation of Bruun and Jensen (2002) was used, which estimates the fraction of SOM in the slow pool from the model parameters under an assumed steady state:

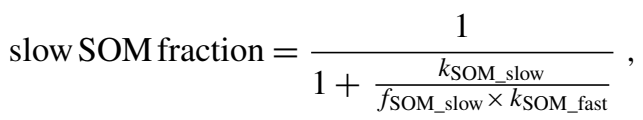

with $k_{\text {SOM_slow }}$ and $k_{\text {SOM_fast }}$ representing the turnover (per day) of the slow and fast SOM pools, respectively, and $f_{\text {SOM_slow }}$ representing the fraction of the fast SOM pool directed towards the slow SOM pool (humification efficiency). This resulted in $83 \%$ of SOM in the slow pool for the original Daisy turnover rates and $49 \%$ in the slow pool for the Bruun et al. (2003) turnover rates (Table 2). For the DSI initialization, the ratio of the area below the aliphatic absorption bands to the area below the aromatic-carboxylate absorption band was used as the ratio of SOM in the fast-cycling SOM pool to SOM in the slow-cycling SOM pool:

$$
\frac{\text { fast SOM }}{\text { slow SOM }}=\frac{\text { A_2 } 2930 \mathrm{~cm}^{-1}}{\text { A_ } 1620 \mathrm{~cm}^{-1}}=\text { DSI. }
$$

Thus, analogous to Eq. (1), the fraction of SOM in the slow pool was calculated with the formula

$$
\text { slow } S O M \text { fraction }=\frac{\text { A_1620 } \mathrm{cm}^{-1}}{\text { A_1620 } \mathrm{cm}^{-1}+\text { A_2930 } \mathrm{cm}^{-1}} \text {, }
$$

with A_2930 $\mathrm{cm}^{-1}$ and A_ $1620 \mathrm{~cm}^{-1}$ being the specific area under the aliphatic and aromatic-carboxylate band, respectively (described in Sect. 2.1). The remaining carbon was allocated to the fast SOM pool. As was mentioned before, three different data inputs for the DSI were used, obtained at drying temperatures of 32,65 and $105^{\circ} \mathrm{C}$, in order to test which drying temperature derived the best proxy for modeling. An example of the change in DRIFTS spectra occurring after several years of bare fallow can be found in Fig. 2 . All DSI model initializations were simulated with both published sets of model parameters. Steady-state initializations 
Table 2. Values of the two Daisy parameter sets used in this study. The parameters consist of turnover rates $(k)$, maintenance respiration (only for SMB, added to the turnover rate), carbon use efficiency (CUE - which divides between carbon assimilated by SMB and lost as $\mathrm{CO}_{2}$ ), the humification efficiency ( $f_{\mathrm{SOM} \text { slow }}$ ) and microbial recycling (part of SMB going directly back to SMB fast at turnover of either SMB pool). A graphical display of the model structure and pools considered within this study is found in Fig. 1.

\begin{tabular}{llll}
\hline Parameter & Mueller et al. (1997) & Bruun et al. (2003) & Unit \\
\hline$k_{\text {SOM_slow }}$ & $2.70 \times 10^{-6^{\mathrm{a}}}$ & $4.30 \times 10^{-5^{\mathrm{c}}}$ & $\mathrm{d}^{-1}$ \\
$k_{\text {SOM_fast }}$ & $1.40 \times 10^{-4^{\mathrm{a}}}$ & $1.40 \times 10^{-4^{\mathrm{a}}}$ & $\mathrm{d}^{-1}$ \\
$k_{\text {SMB_slow }}$ & $1.85 \times 10^{-4^{\mathrm{b}}}$ & $1.85 \times 10^{-4^{\mathrm{b}}}$ & $\mathrm{d}^{-1}$ \\
$k_{\text {SMB_fast }}$ & $1.00 \times 10^{-2^{\mathrm{b}}}$ & $1.00 \times 10^{-2^{\mathrm{b}}}$ & $\mathrm{d}^{-1}$ \\
$k_{\text {AOM_slow }}$ & $1.20 \times 10^{-2^{\mathrm{b}}}$ & $1.20 \times 10^{-2^{\mathrm{b}}}$ & $\mathrm{d}^{-1}$ \\
$k_{\text {AOM_fast }}$ & $5.00 \times 10^{-2^{\mathrm{b}}}$ & $5.00 \times 10^{-2^{\mathrm{b}}}$ & $\mathrm{d}^{-1}$ \\
Maint_SMB_slow & $1.80 \times 10^{-3^{\mathrm{b}}}$ & $1.80 \times 10^{-3^{\mathrm{b}}}$ & $\mathrm{d}^{-1}$ \\
Maint_SMB_fast & $1.00 \times 10^{-2^{\mathrm{b}}}$ & $1.00 \times 10^{-2^{\mathrm{b}}}$ & $\mathrm{d}^{-1}$ \\
CUE_SMB & $0.60^{\mathrm{a}}$ & $0.60^{\mathrm{a}}$ & $\mathrm{kg} \mathrm{kg}^{-1}$ \\
CUE_SOM_slow & $0.40^{\mathrm{b}}$ & $0.40^{\mathrm{b}}$ & $\mathrm{kg} \mathrm{kg}^{-1}$ \\
CUE_SOM_fast & $0.50^{\mathrm{b}}$ & $0.50^{\mathrm{b}}$ & $\mathrm{kg} \mathrm{kg}^{-1}$ \\
CUE_AOM_slow & $0.13^{\mathrm{b}}$ & $0.13^{\mathrm{b}}$ & $\mathrm{kg} \mathrm{kg}^{-1}$ \\
CUE_AOM_fast & $0.69^{\mathrm{b}}$ & $0.69^{\mathrm{b}}$ & $\mathrm{kg} \mathrm{kg}^{-1}$ \\
$f_{\text {SOM_slow }}$ & $0.30^{\mathrm{c}}$ & $\mathrm{kg} \mathrm{kg}$ \\
Part. SMB >SOM_fast (microbial recycling) & $0.10^{\mathrm{a}}$ & $0.40^{\mathrm{a}}$ & $\mathrm{kg} \mathrm{kg}$ \\
Fraction of SOM_slow at steady-state Bruun(2002) equation & $0.40^{\mathrm{a}}$ & 0.49 & $\mathrm{~kg} \mathrm{~kg}^{-1}$ \\
\hline
\end{tabular}

$k$, turnover rate (death rate for SMB); Maint, maintenance respiration (SMB only); CUE, carbon use efficiency; SOM, soil organic matter pools; SMB, soil microbial biomass pools; AOM, added organic matter pools (not considered in this study); Part., partitioning. ${ }^{\text {a }}$ Original Jensen (1997). ${ }^{b}$ Modified by Mueller et al. (1997). ${ }^{c}$ Modified by Bruun et al. (2003).

using Eq. (1) were only simulated with the corresponding parameter set from which they were calculated.

\subsection{Statistical evaluation of model performance}

Statistical analysis was performed with SAS version 9.4 (SAS Institute Inc., Cary, NC, USA). To compare different model initializations, a statistical analysis of squared model errors (SME) was conducted:

$\operatorname{SME}_{x}=\left(\operatorname{obs}_{x}-\operatorname{pred}_{x}\right)^{2}$,

with obs $x$ being the observed value, $\operatorname{pred}_{x}$ the predicted value and $x$ the simulated variable of interest. A linear mixed model with $\mathrm{SME}_{x}$ as the response was then used to test for significant differences between initialization methods. This approach allowed for us to make use of the statistical power of the three Kraichgau and Swabian Jura fields to analyze which initialization was most accurate and to evaluate the trend of the model error with increasing simulation time. In some cases, $\mathrm{SME}_{x}$ were transformed to ensure a normal distribution of residuals (square root transformation for Ultuna SOC and Kraichgau and Swabian Jura SMB-C and fourth root for Kraichgau and Swabian Jura SOC), which was checked by a visual inspection of the normal Q-Q plots and histograms of residuals (Kozak and Piepho, 2018). Random effects were included to account for temporal autocorrelation of $\mathrm{SME}_{x}$ within (a) the same field and (b) the same simula- tion. The model reads as follows:

$$
\begin{aligned}
y_{i j k l} & =\phi_{0}+\alpha_{0 i}+\beta_{0 j}+\gamma_{0 i j}+\phi_{1} t_{k}+\alpha_{1 i} t_{k} \\
& +\beta_{1 j} t_{k}+\gamma_{1 i j} t_{k}+u_{k l}+u_{i j k l},
\end{aligned}
$$

where $y_{i j k l}$ are the $\mathrm{SME}_{x}$ of the simulation using the $i$ th initialization with the $j$ th parameter set, at the $k$ th time in the $l$ th field; $\phi_{0}$ is an overall intercept; $\alpha_{0 i}$ is the main effect of the $i$ th initialization; $\beta_{0 j}$ is the main effect of the $j$ th parameter set; $\gamma_{0 i j}$ is the $i j$ th interaction effect of initialization $\times$ parameter set; $\phi_{1}$ is the slope of the time variable $t_{k} ; \alpha_{1 i} t_{k}$ is the interaction of the $i$ th initialization with time; $\beta_{1 j} t_{k}$ is the interaction of the $j$ th parameter set with time; $\gamma_{1 i j} t_{k}$ is the $i j$ th interaction effect of initialization $\times$ parameter set $\times$ time; $u_{k l}$ is the autocorrelated random deviation at the $k$ th time in the $l$ th field; and $u_{i j k l}$ is the autocorrelated residual error term corresponding to $y_{i j k l}$. The detailed SAS code can be found in the supplementary material. For Ultuna and Bad Lauchstädt, the $u_{k l}$ term was left out, as both trials only had one field. As the Kraichgau and Swabian Jura sites had the exact same experimental setup and duration, these sites were jointly analyzed in the statistical model, but due to completely different setups and durations, this was not possible for Bad Lauchstädt and Ultuna. The full models with all fixed effects were used to compare different correlation structures for the random effects including (i) temporal autocorrelation (exponential, spherical, Gaussian), (ii) compound symmetry, (iii) a simple random effect for each different field and simu- 


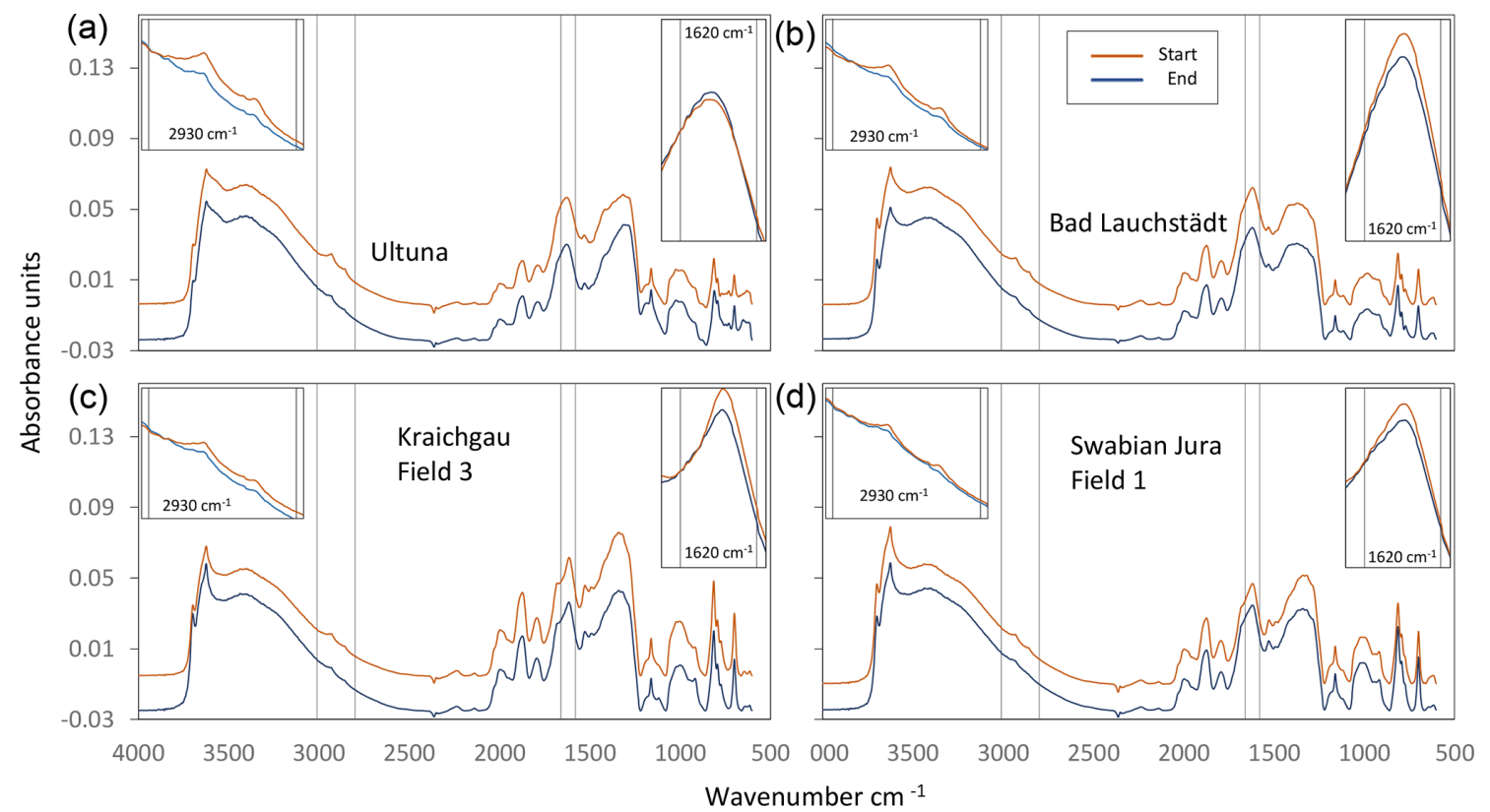

Figure 2. Examples of baseline-corrected and vector-normalized DRIFTS spectra of bulk soil samples (dried at $105^{\circ} \mathrm{C}$ ) of the first and last year of the bare fallow plots at four sites. Fallow periods were 50 years (a Ultuna), 24 years (b Bad Lauchstädt) and 7 years (c Kraichgau and d Swabian Jura). Small pictures in (a) to (d) are zoomed-in versions of the $2930 \mathrm{~cm}^{-1}$ band (left) and the $1620 \mathrm{~cm}^{-1}$ band (right). For better visibility, the full spectra pictures have a $y$-axis offset $(+0.02$ for samples from the start), while zoomed-in versions share a common baseline. More details on the sites are in Table 3.

lation, and (iv) a random intercept and slope of the time variable (with allowed covariance between both) for each field and initialization method. A residual maximum-likelihood estimation of model parameters was used, and the best-fitting random-effect structure for this model was selected using the Akaike information criterion as specified by Piepho et al. (2004). Then a stepwise model reduction was conducted until only the significant effects $(p<0.05)$ remained in the final statistical model. Because a mixed model was used, the Kenward-Roger method was applied for estimating the degrees of freedom (Piepho et al., 2004) and to compute post hoc Tukey-Kramer pairwise comparisons of means.

\subsection{Model optimization and observation weighting for Bayesian calibration}

Optimization of parameters $k_{\mathrm{SOM} \_s l o w}, k_{\mathrm{SOM} \text { fast }}$ and the humification efficiency ( $\left.f_{\text {SOM_slow }}\right)$ was performed using a Bayesian calibration approach. These parameters were chosen as only they have a considerable impact on the rate of native SOM loss (see further details in the Supplement Sect. S12.2 ). The Bayesian calibration method uses an iterative process to simulate what the distribution of parameters would be given the data and the model. It combines a random walk through the parameter space with a probabilistic approach on parameter selection.
The differential evolution adaptive metropolis algorithm (Vrugt, 2016) implemented in UCODE_2014 (Lu et al., 2014; Poeter et al., 2014) was used for the Bayesian calibration in this study. As no Bayesian calibration of Daisy SOM parameters has been done before, noninformative priors were used. The main drawback of noninformative priors is that they can have longer computing times, but, as was shown by Lu et al. (2012), with sufficient data and simulation durations, the posterior distributions are very similar to using informed priors. Ranges were set far beyond published parameters with $1.4 \times 10^{-2}$ to $1.4 \times 10^{-6} \mathrm{~d}^{-1}$ for $k_{\mathrm{SOM} \_ \text {fast }}$ and $1.4 \times 10^{-3}$ to $5 \times 10^{-7} \mathrm{~d}^{-1}$ for $k_{\mathrm{SOM}}$ slow. The parameter $f_{\text {SOM_slow }}$ had to be more strongly constrained as without constraints it tended to run into unreasonable values of up to $99 \%$ humification. The limits were therefore set to 0.05 to 0.35 , which are $\pm 5 \%$ of the two published parameter sets and represent the upper boundaries of other similar models (e.g., Ahrens et al., 2014). The default UCODE_2014 Gelman-Rubin criterion (Gelman and Rubin, 1992) value of 1.2 was chosen for the convergence criteria. A total of 15 chains were run in parallel with a time step of $0.09 \mathrm{~d}$ in Expert-N 5.0 (this was the largest time step and fastest computation where the simulation results of water flow, temperature and hence SOM pools were unaltered compared to smaller time steps). It was ensured that at least 300 runs per chain were carried out after the convergence criterion was satisfied. 
In Bayesian calibration, a proper weighing of observations is needed in order to achieve a diagonal weight matrix of residuals (proportional to the inverse of the variancecovariance matrix) and to ensure that residuals are in the same units (Poeter et al., 2005, p. 18 ff.). This included several steps. A differencing removed autocorrelation in the individual errors in each model run of the Bayesian calibration itself (the first measurement of each kind of data at each field was taken as raw data, for any repeated measurement the difference from this first measurement was taken instead of the raw data). Details on differencing are provided in chapter 3 of the UCODE_2005 manual (Poeter et al., 2005). To account for varying levels of heterogeneity of different fields in the weighting, a linear mixed model was used to separate the variance in observations from different fields originating from natural field heterogeneity from the variance originating from measurement error. To do so, a linear mixed model with a random slope and intercept of the time effect for each experimental plot was fitted to the SOC, SMB-C and DSI data for each field individually:

$y_{k l}=\phi_{0}+\phi_{1} t_{k}+u_{l}+u_{k}+u_{k l}$,

where $y_{k l}$ is the modeled variable at the $k$ th time on the $l$ th plot, $\phi_{0}$ is the intercept, $\phi_{1}$ is the slope of the time variable $t_{k}$, $u_{l}$ is the random intercept, $u_{k}$ is the autocorrelated random deviation of the slope and $u_{k l}$ is the autocorrelated residual error term corresponding to $y_{k l}$.

The error variance in each type of measurement (DSI, SMC-C, SOC) at each field $\sigma_{f M}^{2}=\sigma_{u_{k}}^{2}+\sigma_{u_{k l}}^{2}$ was then used for weighting of observations, excluding the field variance $\sigma_{u_{l}}^{2}$ from the weighting scheme. This error variance was used in UCODE_2014 to compute weighted model residuals for each observation as follows:

$\mathrm{w} \_S M E_{x}=\frac{\left(\operatorname{obs}_{x}-\operatorname{pred}_{x}\right)^{2}}{\sigma_{f M}^{2}}$,

where $\mathrm{w} \_\mathrm{SME}_{x}$ is the weighted squared model residual, obs ${ }_{x}$ is the observed value, $\operatorname{pred}_{x}$ is the predicted value and $\sigma_{f M}^{2}$ is the error variance in the $M$ th type of measurement at each field. All $\mathrm{w}_{-} \mathrm{SME}_{x}$ values are summed up to the sum of squared weighted residuals, which is the objective function used in UCODE_2014 (Poeter et al., 2014). By this procedure, observations with higher measurement errors have a lower influence in the Bayesian calibration.

Since the medium-term experiments had a much higher measurement frequency, it was also tested whether giving each experiment the same weight would improve the results of the Bayesian calibration (equal weight calibration). In this case an additional group weighting term was introduced for groups of observations, representing different datasets at the different sites. This weighting term is internally multiplied with each $\mathrm{w}_{-} \mathrm{SME}_{x}$ value in UCODE_2014 and was calculated as

w_G $\mathrm{G}_{x}=\frac{1}{\left(n_{\mathrm{obs}} \times n_{\mathrm{par}} \times n_{\mathrm{f}}\right)}$, where $\mathrm{w}_{-} \mathrm{G}_{x}$ is the weight multiplier for each observation, $n_{\text {obs }}$ is the number of observations per parameter, $n_{\text {par }}$ is the number of parameters per field, and $n_{\mathrm{f}}$ is the number of fields per site. This weighing assures that, with the exact same percentage of errors, each site would have the exact weight of 1 .

The influence of several factors was assessed in this Bayesian calibration: the use of individual sites compared to combining sites, including an equal weight (EW, as described above) vs. original weight (OW) weighting only by error variance, and the effect of including and excluding the DSI ( \pm DSI) in the Bayesian calibration. Therefore, seven Bayesian calibrations were conducted in total: (1-4) four for each individual site with original weight and the DSI, i.e., Ultuna, Bad Lauchstädt, Kraichgau and Swabian Jura; (5) equal weight calibration for all sites combined using the DSI; (6) original weight calibration for all sites combined without using the DSI in the Bayesian calibration (only for initial pool partitioning); and (7) original weight calibration for all sites combined using the DSI. The comparison of these seven Bayesian calibrations was designed to assess the effect of the site on the calibration, as well as the effect of the DSI and of user weighting decisions.

\section{Results}

\subsection{Dynamics of SOC, SMB-C and DRIFTS during bare fallow}

All bare fallow plots lost SOC over time, with the severity of SOC loss varying between soils and climates at the different sites. The Bad Lauchstädt site experienced the slowest carbon loss (7\% of initial SOC in 26 years), while SOC at Ultuna and Kraichgau was lost at much faster rates (Ultuna, $39 \%$ of initial SOC in 50 years; Kraichgau, on average $9 \%$ of initial SOC in 7 years; Table 3). In the Swabian Jura Field 1 the SOC loss was comparable to that of Kraichgau (about $10 \%$ of initial SOC in 7 years) but was much less in fields 2 and 3. Some miscommunication with the field owner's contractors led to unwanted manure addition and field plowing in Swabian Jura fields 2 and 3 in 2013; hence results of these two fields after the incident in 2013 were excluded. The DRIFTS spectra revealed that the aliphatic carbon band area $\left(2930 \mathrm{~cm}^{-1}\right)$ decreased rather fast after the establishment of bare fallow plots, while the aromatic-carboxylate band area $\left(1620 \mathrm{~cm}^{-1}\right)$ showed only minor changes and no consistent trend (Fig. 2). The assumed fraction of SOC in the slow SOM pool according to the DSI at $105^{\circ} \mathrm{C}$ changed from the initial range of $54 \%$ to $80 \%$ to the range of $76 \%$ to $99 \%$ at the end of the observational period (Table 3, Fig. S3). The SMB$\mathrm{C}$ reacted even more rapidly to the establishment of fallow and halved on average for all fields within a 7 year duration (Table 3). 


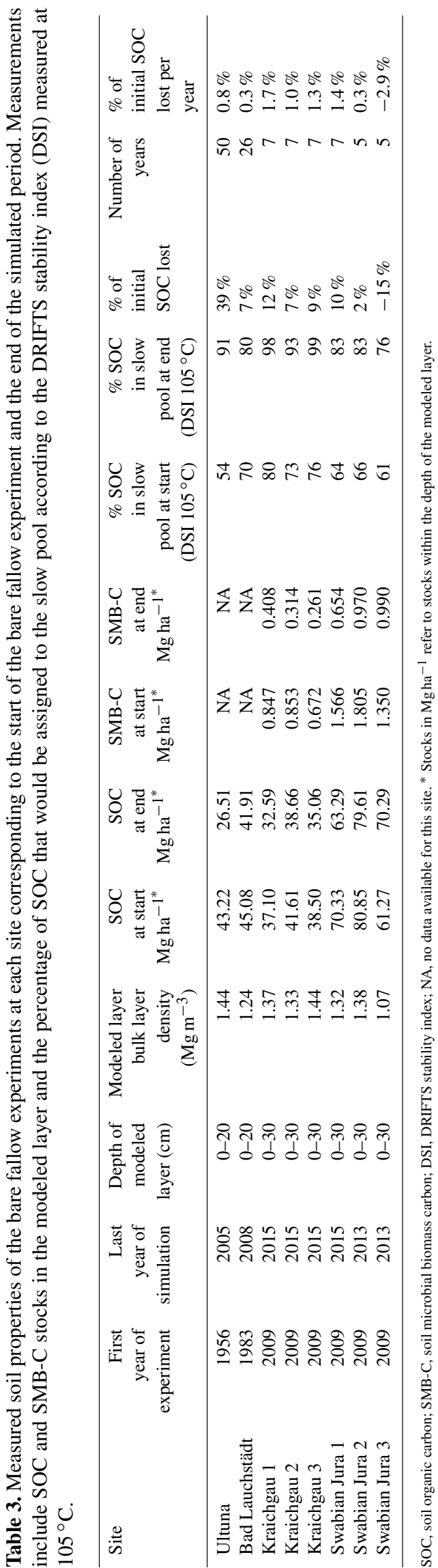

\subsection{Comparison of the different model initializations}

The observed trend of SOC loss with ongoing bare fallow duration was also found in all simulations (Figs. 3 and S4). For Ultuna, simulated SOC loss in all cases underestimated measured loss, while for Bad Lauchstädt, simulated SOC losses consistently overestimated measured losses. At Kraichgau sites, SOC loss was underestimated by the models but with the Bruun et al. (2003) parameter set yielding simulated values closer to actual measurements. In the Swabian Jura, both parameter sets underestimated SOC loss. The decline of SMB-C in the Kraichgau and Swabian Jura (Fig. 4) occurred more rapidly than that of SOC, though SMB-C had higher variability in measurements. The parameter sets with steady-state assumptions marked the upper and lower boundaries of the SMB-C simulations, but the DRIFTS stability index (DSI) initializations were closer to the measured values (with the exception of Swabian Jura Field 3). For brevity only simulations of Field 1 for Kraichgau and Swabian Jura are shown. Simulation results for fields 2 and 3 are found in the supplemental material (Fig. S5 for SOC simulations and Fig. S6 for SMB-C).

The statistical analysis of the model error revealed the effect of the parameter set was site dependent. The three-way interaction of initialization, parameter set and time $\gamma_{1 i j} t_{k}$ was significant for all but Bad Lauchstädt SOC, where only the parameter set had a significant effect. In the case of $\mathrm{Bad}$ Lauchstädt, the model error was significantly lower with the slower Muelle (1997) SOM turnover parameter set, while for the rest of the tested cases, the faster Bruun et al. (2003) set performed significantly better (Table 4). For Ultuna and Kraichgau and Swabian Jura SOC, the steady-state assumption with Mueller et al. (1997) parameters had the highest model error, while the steady-state assumption with Bruun et al. (2003) parameters had the lowest model error of all simulations, being similar to DSI initializations at Kraichgau and Swabian Jura. However, there was a statistically significantly lower SOC model error with the DSI using the $105^{\circ} \mathrm{C}$ drying temperature than there was using the lower drying temperatures for the Ultuna site. For SMB-C simulations at the Kraichgau and Swabian Jura sites, however, the errors were lowest for the DSI initialization using the $105^{\circ} \mathrm{C}$ drying temperature with Bruun et al. (2003) parameters and significantly lower than both steady-state initializations. Of the DSI initializations using different drying temperatures, the model error was always lowest when using the $105^{\circ} \mathrm{C}$ drying temperature initialization compared to 32 and $65^{\circ} \mathrm{C}$ (significant for Ultuna, as well as for Kraichgau and Swabian Jura SMB-C using Mueller et al. (1997) parameters). As initializations with the DSI using the $105^{\circ} \mathrm{C}$ drying temperature consistently performed best of all three DSI initializations, only DSI spectra of soils dried at $105^{\circ} \mathrm{C}$ were used for the Bayesian calibration. 


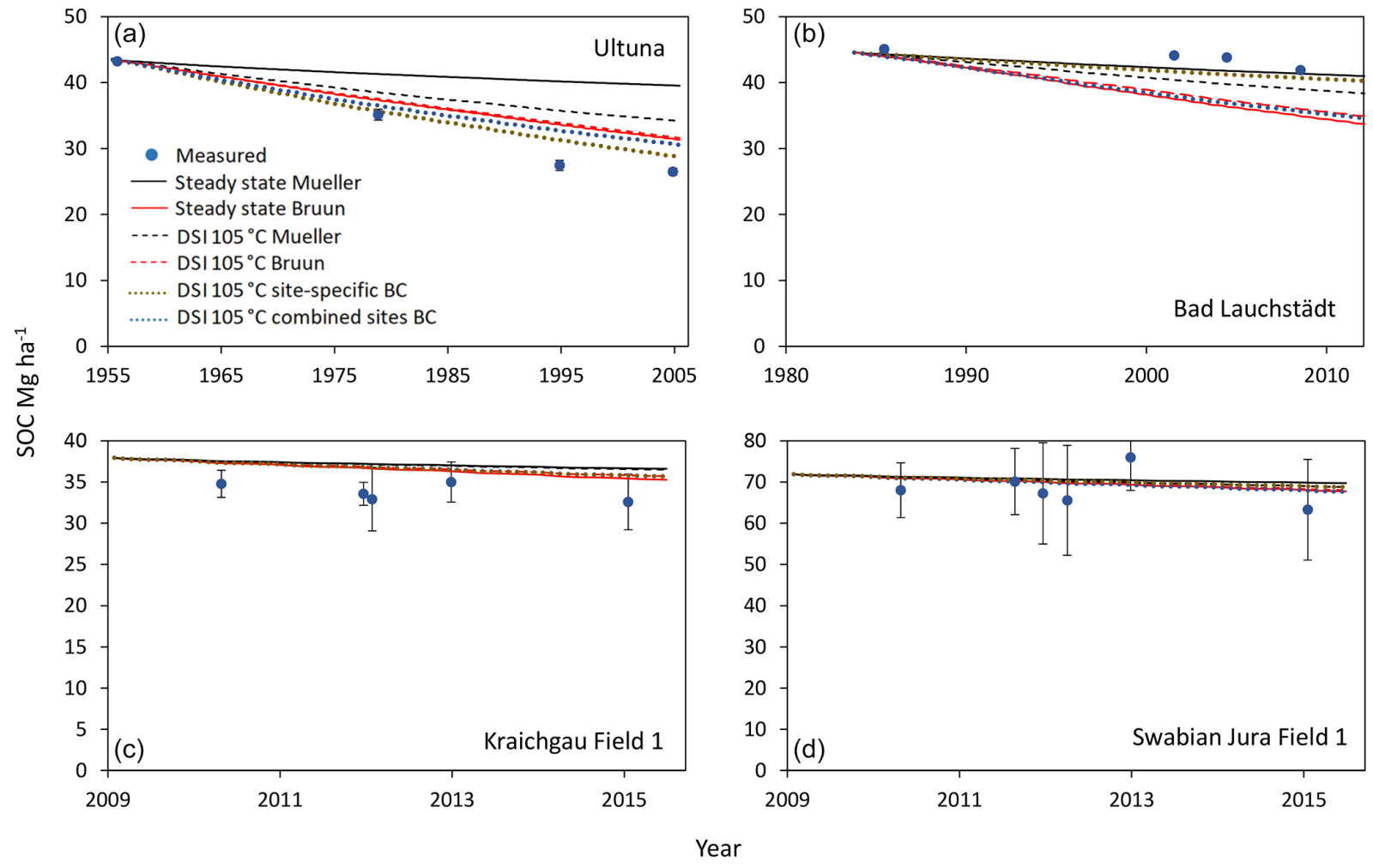

Figure 3. Example of SOC simulations from Ultuna (a), Bad Lauchstädt (b), Kraichgau Field 1 (c) and Swabian Jura Field 1 (d). Initializations were carried out (i) assuming a steady state using the formula of Bruun and Jensen (2002) (Eq. 1) with turnover rates of both Mueller et al. (1997) and Bruun et al. (2003) and (ii) by the DRIFTS stability index (DSI) at a $105^{\circ} \mathrm{C}$ drying temperature using both turnover rates for simulations (simulations using the other drying temperatures for the DSI are in the supplementary material). The site-specific and the combined-sites Bayesian calibrations (BC) are also displayed. Bars indicate the standard deviation of measured values of all plots $(n=3)$ per field.
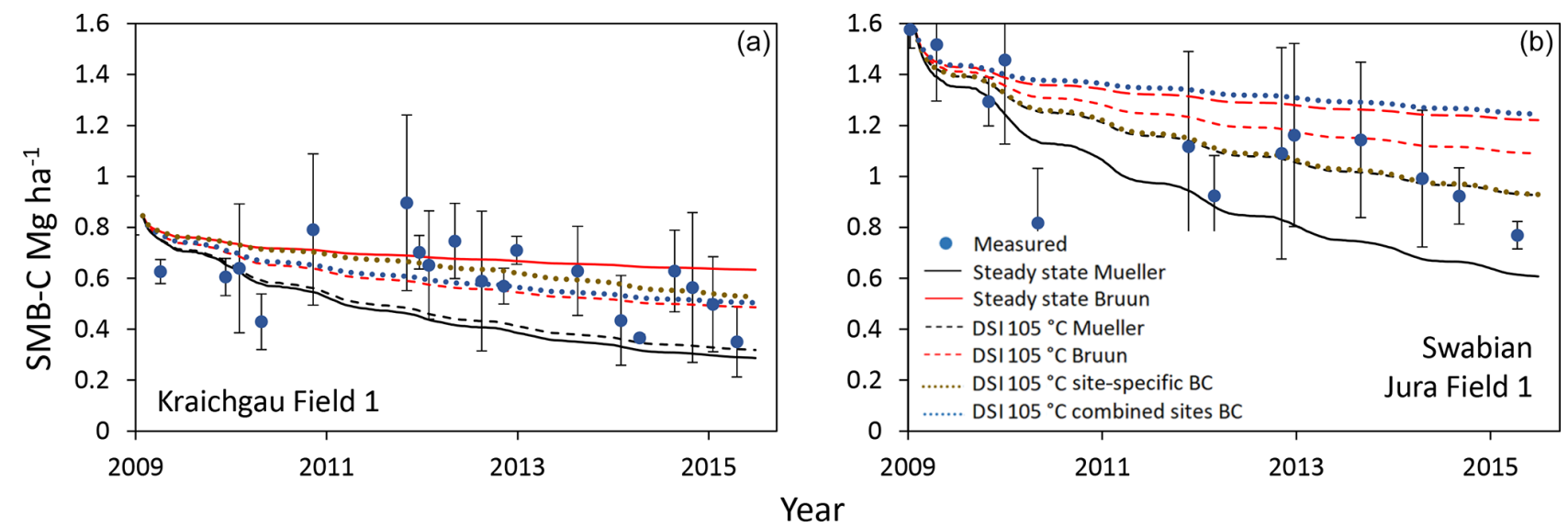

Figure 4. Example SMB-C simulations for Kraichgau Field 1 (a) and Swabian Jura Field 1 (b). Initializations were carried out (i) assuming a steady state using the formula of Bruun and Jensen (2002) with turnover rates of Mueller et al. (1997) and Bruun et al. (2003) and (ii) by the DRIFTS stability index (DSI) at a $105^{\circ} \mathrm{C}$ drying temperature using both turnover rates for simulations (simulations using the other drying temperatures for DRIFTS are in the supplementary material). The site-specific and the combined-sites Bayesian calibrations (BC) are also displayed. Bars indicate the standard deviation of measured values of all plots $(n=3)$ per field. 
Table 4. Effect of the initialization method on simulation errors. Displayed are estimated least-squares means of the absolute error of Daisy bare fallow simulations of SOC and SMB-C for the sites of Ultuna, Bad Lauchstädt, and Kraichgau and Swabian Jura combined. Means are the estimate for the end of the simulation period (number of years in brackets). Different capital letters indicate significant differences $(p<0.05)$ within columns (not tested between sites). For Bad Lauchstädt, the initialization effect was nonsignificant, so only the least-squares means for the effect of the parameter set are displayed.

\begin{tabular}{|c|c|c|c|c|c|}
\hline \multirow[b]{2}{*}{ Parameter set } & \multirow[b]{2}{*}{$\begin{array}{l}\text { Initialization } \\
\text { method of } \\
\text { SOM pools }\end{array}$} & \multirow{2}{*}{$\begin{array}{l}\text { Ultuna (50 years) } \\
\text { Least-squares } \\
\text { means of errors } \\
\left(\mathrm{SOC} \mathrm{Mg} \mathrm{ha}^{-1}\right)\end{array}$} & \multirow{2}{*}{$\begin{array}{l}\text { Bad Lauchstädt (23 years) } \\
\text { Back-transformed } \\
\text { least-squares means } \\
\text { of errors } \\
(\text { SOC Mg ha }\end{array}$} & \multirow{2}{*}{ 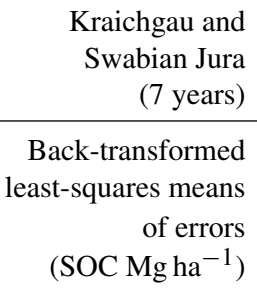 } & \multirow{2}{*}{$\begin{array}{r}\begin{array}{r}\text { Kraichgau and } \\
\text { Swabian Jura } \\
(7 \text { years })\end{array} \\
\text { Least-squares } \\
\text { means of errors } \\
\left(\text { SMB-C } \mathrm{Mg} \mathrm{ha}^{-1}\right)\end{array}$} \\
\hline & & & & & \\
\hline \multirow[t]{4}{*}{ Mueller et al. (1997) } & $\begin{array}{l}\text { Ratio of steady- } \\
\text { state assumption }\end{array}$ & $13.91^{\mathrm{A}}$ & $2.22^{\mathrm{A}}$ & $4.50^{\mathrm{A}}$ & $0.354^{\mathrm{A}}$ \\
\hline & $\begin{array}{l}\text { Band area ratio of } \\
\text { DRIFTS at } 32^{\circ} \mathrm{C}\end{array}$ & $10.86^{\mathrm{B}}$ & & $4.50^{\mathrm{A}}$ & $0.317^{\mathrm{AB}}$ \\
\hline & $\begin{array}{l}\text { Band area ratio of } \\
\text { DRIFTS at } 65^{\circ} \mathrm{C}\end{array}$ & $10.06^{\mathrm{C}}$ & & $4.42^{\mathrm{A}}$ & $0.274^{\mathrm{ABC}}$ \\
\hline & $\begin{array}{l}\text { Band area ratio of } \\
\text { DRIFTS at } 105^{\circ} \mathrm{C}\end{array}$ & $8.52^{\mathrm{D}}$ & & $4.28^{\mathrm{A}}$ & $0.205^{\mathrm{CD}}$ \\
\hline \multirow[t]{4}{*}{ Bruun et al. (2003) } & $\begin{array}{l}\text { Ratio of steady- } \\
\text { state assumption }\end{array}$ & $5.84^{\mathrm{H}}$ & $6.01^{\mathrm{B}}$ & $3.12^{\mathrm{B}}$ & $0.231^{\mathrm{BCD}}$ \\
\hline & $\begin{array}{l}\text { Band area ratio of } \\
\text { DRIFTS at } 32^{\circ} \mathrm{C}\end{array}$ & $7.06^{\mathrm{E}}$ & & $3.31^{\mathrm{B}}$ & $0.179^{\mathrm{CDE}}$ \\
\hline & $\begin{array}{l}\text { Band area ratio of } \\
\text { DRIFTS at } 65^{\circ} \mathrm{C}\end{array}$ & $6.75^{\mathrm{F}}$ & & $3.30^{\mathrm{B}}$ & $0.160^{\mathrm{DE}}$ \\
\hline & $\begin{array}{l}\text { Band area ratio of } \\
\text { DRIFTS at } 105^{\circ} \mathrm{C}\end{array}$ & $6.15^{\mathrm{G}}$ & & $3.25^{\mathrm{B}}$ & $0.131^{\mathrm{E}}$ \\
\hline
\end{tabular}

SOM, soil organic matter pools; SOC, soil organic carbon; SMB-C, soil microbial biomass carbon; DRIFTS, diffuse reflectance mid-infrared Fourier transform spectroscopy.

\subsection{Informed turnover rates of the Bayesian calibration}

The posterior distribution of parameters from the Bayesian calibration differed considerably between the different calibrations for individual sites, but there were also differences between different weighting schemes or when performing the Bayesian calibration without using the DSI (Fig. 5). The highest probability turnover of the fast SOM pool ( $\left.k_{\mathrm{SOM} \text { fast }}\right)$ was 1.5 and 3 times faster for Ultuna and Kraichgau, respectively, when compared to initial rates $\left(1.4 \times 10^{-4} \mathrm{~d}^{-1}\right.$ for both parameters sets), which fitted well for Bad Lauchstädt and Swabian Jura. For the slow SOM pools ( $\left.k_{\text {SOM_slow }}\right)$, the Bad Lauchstädt, Kraichgau and Swabian Jura site calibrations were in between the two published parameter sets but tended towards the slower rates $\left(2.7 \times 10^{-6} \mathrm{~d}^{-1}\right.$ by Mueller et al., 1997), while the optimum for Ultuna was exactly at the fast rates of Bruun et al. $\left(2003 ; 4.3 \times 10^{-5} \mathrm{~d}^{-1}\right)$. The humification efficiency ( $f_{\text {SOM_slow }}$ ) was not strongly constrained in the Bayesian calibration, except for the Kraichgau site, where it ran into the upper boundary of 0.35 . This trend towards higher humification also existed for the other sites but to a lesser extent than for Kraichgau.

The different calibrations of the combination of all sites under different weightings and with or without the DSI led to considerable differences in the posteriors (Fig. 5). When combining the sites with the artificial equal weighting, the posterior distribution of all three parameters was the widest, basically covering the range of all four site calibrations. With the original weighting scheme, only informed by the variance in the data, the posteriors were narrower for all parameters, with the optima of $k_{\text {SOM_fast }}$ being slightly faster than the two (similar) published rates. The optima of $k_{\mathrm{SOM} \text { _slow }}$ were slightly slower than Bruun et al. (2003) but much faster than Mueller et al. (1997), and $f_{\text {SOM_slow }}$ was even above the higher Bruun et al. (2003) value of 0.3. The use of the original weighting scheme without the use of the DSI in the Bayesian calibration did not constrain the $f_{\text {SOM_slow }}$ at all and had faster $k_{\text {SOM_slow }}$ and slower $k_{\text {SOM_fast }}$ than the one using the DSI. Both these Bayesian calibrations using the original weighting (with and without the DSI) showed a trend 

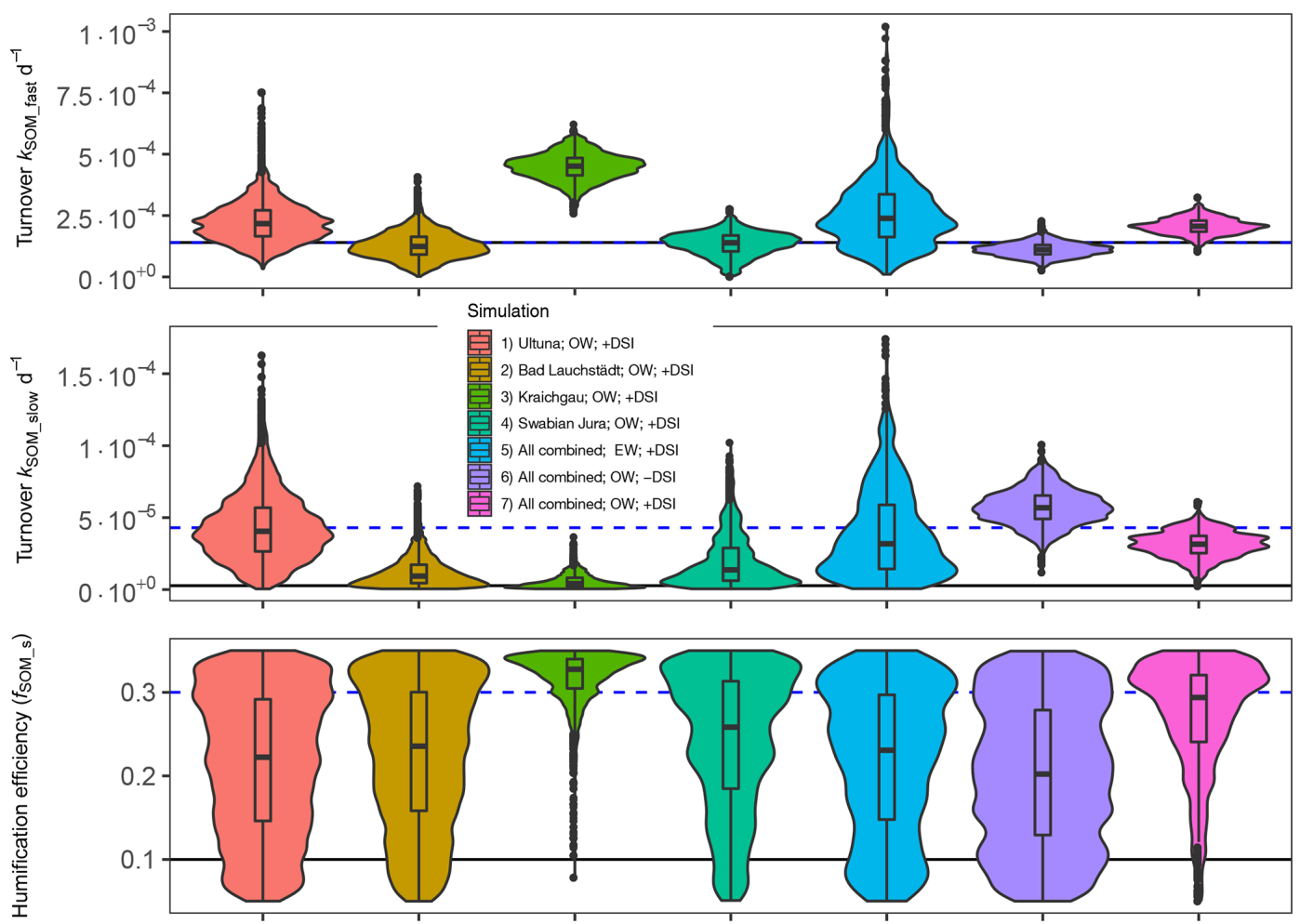

Figure 5. Violin plots of the parameter distributions, obtained by the Bayesian calibration using only the individual sites (1-4) and all sites combined (5-7) with different weighing schemes (OW, original weight; EW, equal weight calibration; \pm DSI indicates whether the DSI data were used for calibration). The black line corresponds to the parameters of Mueller et al. (1997) and the dashed blue line to the parameters of Bruun et al. (2003). Note that the turnover $k_{\text {SOM_fast }}$ parameter (top of the figure) is the same in both Mueller et al. (1997) and Bruun et al. (2003).

towards slightly faster turnover than suggested by Bruun et al. (2003).

There was a strong negative correlation between $k_{\mathrm{SOM}}$ fast and $k_{\text {SOM_slow }}$ parameters for all but the Bad Lauchstädt calibration (Fig. S7). When the DSI was not included in the Bayesian calibration, this negative correlation was stronger than when it was included (Fig. 6). The parameters $k_{\text {SOM_fast }}$ and $f_{\text {SOM_slow }}$ were always positively correlated, most strongly for Kraichga (0.49) and Swabian Jura (0.38) but only weakly for the long-term sites. The correlations between the parameters $k_{\text {SOM_slow }}$ and $f_{\text {SOM_slow }}$ were generally low and both positive and negative. The parameters with the highest probability density of the calibrations combining all sites for $f_{\text {SOM_slow }}, k_{\text {SOM_fast }}$ and $k_{\text {SOM_slow }}$ in that order were $0.34,2.29 \times 10^{-4}$ and $3.25 \times 10^{-5}$ for the original weight calibration and $0.06,9.58 \times 10^{-5}$ and $5.54 \times 10^{-5}$ for the calibration using original weights and no DSI. These results suggest that turnover rates of $k_{\text {SOM_slow }}$ could be similar or faster than those of $k_{\mathrm{SOM}}$ fast without the use of the DSI. About $10 \%$ of the simulations of the Bayesian calibration without the DSI even had a faster $k_{\mathrm{SOM} \text { _slow }}$ than $k_{\mathrm{SOM} \text { fast }}$.

\section{Discussion}

\subsection{How useful is the DRIFTS stability index?}

A search for suitable proxies for SOM pool partitioning into SOM model pools that correspond to measurable and physicochemically meaningful quantities is of high interest (Abramoff et al., 2018; Bailey et al., 2018; Segoli et al., 2013). The results of this study confirm the hypothesized usefulness of the DSI proxy in assessing the current state of SOM for pool partitioning to model SOC for several soils across Europe. This is particularly relevant given that changes in crop genotype and rotation and agricultural management and the rise of average temperatures in recent decades as well as land use changes, such as draining of soils or deforestation, in recent centuries have altered the quality and quantity of carbon inputs to soil. Consequently, the steady-state assumption for model initialization is not likely to be valid. Demyan et al. (2012) showed that, with a careful selection of integration limits for absorbance band areas, the DSI through identifying organic contributions in DRIFTS spectra is a sensitive indicator of SOM stability if mineralogy is similar (despite acknowledged mineral interference). Combined with a higher temperature $\left(105^{\circ} \mathrm{C}\right)$ for soil drying 
(a) All combined; EW; +DSI (5)
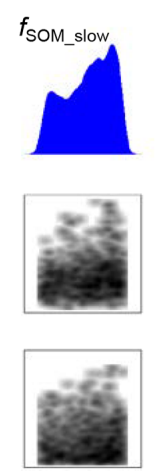
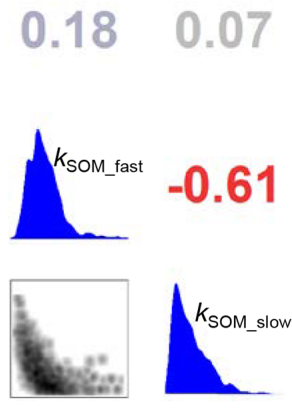

(b) All combined; OW
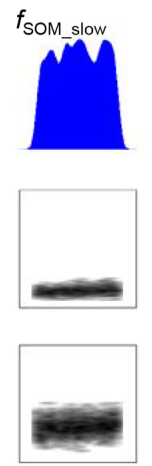
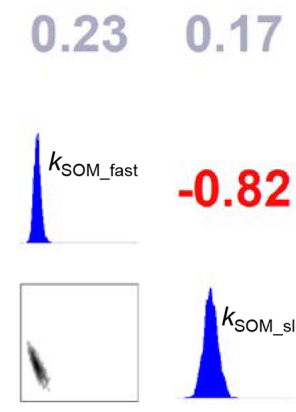

(6)

(c) All combined; OW; +DSI (7)
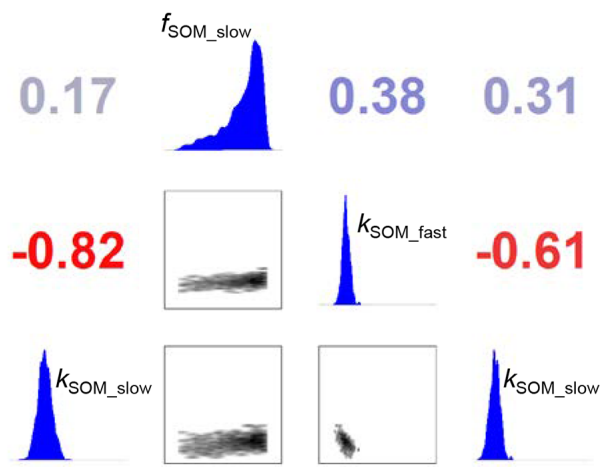

Figure 6. Correlation matrices of posterior distributions from the Bayesian calibrations of (a) equal weight calibration for all sites combined using the DSI (calibration 5), (b) original weight calibration for all sites combined without using the DSI (calibration 6) and (c) original weight calibration for all sites combined using the DSI (calibration 7). The plots of individual site simulations (calibrations 1-4) can be found in the Supplement.

prior to DRIFTS analysis, a strong correlation between the portion of centennially persistent SOC and the DSI (Fig. S2) was found in our study, which supports the hypothesis that the DSI might be of general applicability across sites. Results from modeling corroborated the usefulness of the DSI for SOM pool partitioning for soils of different properties across Europe. The statistical analysis of the model error for both SOC and SMB-C showed clearly that the DSI can improve poor model performance, especially when the slower turnover rates of Mueller et al. (1997) were used. When model performance is already satisfactory, the natural variability in the DSI can make model performance worse, as in the case of Ultuna SOC with Bruun et al. (2003) parameters, but this reduction was minor compared to the improvement the DSI had over steady-state assumptions at Ultuna with Mueller et al. (1997) rates. The better results for U1tuna with the Bruun et al. (2003) steady state might also just be an effect of turnover times still being too slow, and hence the more SOC in the fast pool, the faster turnover is in general and the lower the model error. This was also indicated by faster optima by the Bayesian calibration compared to both published turnover rates. In the case of the Chernozem of Bad Lauchstädt, only turnover rates had an influence on model performance and its SOC turnover was overestimated by both parameter sets (Fig. 3). It was previously suggested that the high SOC storage capacity of this site is a result of cation-bridging due to a high content of adsorbed cations (Ellerbrock and Gerke, 2018). Additionally, there is evidence of black carbon at the site (e.g., the high thermal stability found by Demyan et al., 2013). Therefore, a possible reason for an overestimation of SOC turnover in Bad Lauchstädt might be that Daisy only considers clay content as a stabilizing mechanism. Nevertheless, the use of the DSI was also suitable for Bad Lauchstädt, as there was no significant difference in model performance compared to a steady state.
The range of different sites, soils and climatic conditions of Europe represented within this study suggests the robustness of the DSI as a proxy for SOM quality and SOM pool division for a large environmental gradient. Hence, it would be an improvement over assuming a steady state of SOM wherever there is a lack of detailed information on carbon inputs and climatic conditions. Considering the timescales at which SOM develops, this is almost anywhere, as detailed data are available at best for $<200$ years, which is not even one halflife of the slow SOM pool.

So far, studies that have assessed SOM quality and pool division proxies, using either the thermal stability of SOM (Cécillon et al., 2018) or size-density fractionation (Zimmermann et al., 2007), only indirectly related the proxies to inversely modeled SOM pool distributions, using machine learning and rank correlations. In contrast, our study showed that the DSI is a proxy which can be directly used for pool initialization. The DSI also makes sense from the perspective of energy content, as microorganisms can obtain more energy from the breakdown of aliphatic than aromatic-carboxylate carbon compounds (e.g., Good and Smith, 1969), and therefore aliphatic carbon is primarily targeted by microorganisms (hence has faster turnover), as previously shown for bare fallow (Barré et al., 2016).

The two distinct absorption bands for aliphatic and aromatic-carboxylate carbon bonds of the DSI fit well to the two SOM pool structures of Daisy, and the simulation of carbon flow through the soil in Daisy is very similar to several established SOM models such as SoilN, ICBM and CENTURY. It is therefore likely that, with calibration, the DSI could be used as a general proxy for SOM models with two SOM pools and a humification efficiency $\left(f_{\text {SOM_slow }}\right.$ in Daisy). The parameter correlations between $k_{\text {SOM_slow, }}$ $k_{\text {SOM_fast }}$ and $f_{\text {SOM_slow }}$ according to the Bayesian calibrations also suggest that without a pool-partitioning proxy, modifying any one parameter can lead to similar results in 
terms of SOC and SMB-C simulation. A clear distinction between fast and slow pools needs a pool-partitioning proxy, as can be seen by faster $k_{\text {SOM_slow }}$ than $k_{\text {SOM_fast }}$ for some of the simulations of the Bayesian calibration without using the DSI. Assigning the DSI to Daisy reduced parameter correlations and led to a clear distinction between fast and slow SOM pools.

The DRIFTS absorption band for aliphatic carbon is most resolved when applying a $105^{\circ} \mathrm{C}$ drying temperature to samples prior to analysis (Laub et al., 2019). The current study's modeling results corroborated the finding that the DSI should be obtained from measurements after drying at $105{ }^{\circ} \mathrm{C}$, with the performance of the DRIFTS initializations being always in the order $105^{\circ} \mathrm{C}>65^{\circ} \mathrm{C}>32^{\circ} \mathrm{C}$ drying temperature (differences being sometimes but not always significant).

Compared with the other proxies for SOM quality discussed above, the measurements by DRIFTS are inexpensive and relatively simple, and the equipment of the same manufacturer is standardized. This should also constrain variability between different laboratories and be attractive for large-scale applications with large sample numbers, for example to initialize simulations at the regional scale. However, for standardization of the DSI for model initialization, one needs to address how the type of spectrometer (e.g., detector type) influences the spectra, if water and mineral interferences (Nguyen et al., 1991) in the spectra can be further reduced, and if a mathematical standardization of the spectra and the DSI (across instruments and water contents) is possible. While a complete elimination of mineral interference is not possible, a careful selection of integration limits and the use of a local baseline minimize mineral interference of DRIFTS spectra from bulk soils. This mostly selects the top part of the $1620 \mathrm{~cm}^{-1}$ band area, which corresponds to the part that is reduced or completely lost when SOC is destroyed (Demyan et al., 2013; Yeasmin et al., 2017). Other approaches such as spectral subtraction of ashed samples or HF destruction of minerals prior to DRIFTS analysis have been developed in the attempt to obtain spectra of pure SOC. All are rather labor intensive and still produce artifacts, as it is not possible to destroy only the minerals or only the SOC without altering the respective other fraction (Yeasmin et al., 2017). Hence, we think that the selected integration limits might represent at this point the most feasible option for obtaining a robust and cost-effective proxy of SOC quality for modeling. The strong correlation of the DSI and centennially persistent SOC as well as the model results of this study seem to corroborate this. The method of DSI estimation might be improved by a study of the best integration limits optimizing the fit of the DSI and centennially persistent SOC, which would require more bare fallow experiments than in this study. From a conceptual perspective the DSI probably relates mainly to chemical recalcitrance of SOM present in different SOM fractions. In that respect it is different from physical light and heavy fraction separation approaches as each of these fractions is very heterogeneous. For example, the light fraction has strong absorbance at both aliphatic and aromatic-carboxylate carbon bands (Calderón et al., 2011), so it could be that within each fraction, aliphatic carbon is preferentially consumed by microorganisms. Thus, the DSI reflects physicochemically stabilized SOC (mainly mineral association in the case of bare soils) as also suggested by the correlation of the ratio of $1620 \mathrm{~cm}^{-1} / 2930 \mathrm{~cm}^{-1}$ absorption bands to the ratio of mineral-associated carbon / light fraction carbon (Demyan et al., 2012). The relationship to mineral association in many models is represented by a texture adjustment factor. On the other hand, the DSI does not directly relate to aggregated (i.e., occluded) SOM, and its applicability in models focusing on aggregation needs to be evaluated (i.e., by a separate spectral analysis of occluded and remaining fractions).

The recent coupling of pyrolysis with DRIFTS (Nkwain et al., 2018) might be a further analytical advancement of the DSI, as it overcomes mineral interferences in the spectra. However, this technique is more complex due to a larger number of visible organic absorption bands, including $\mathrm{CO}_{2}$ that develops from the pyrolysis, which makes it not easily applicable to established two-pool models such as Daisy. In addition, a considerable portion (30\%-40\%) of SOM is not pyrolyzed and therefore not recorded in the spectra. In summary, despite the acknowledged shortcomings, the DSI was useful to partition SOM between pools and will be even more so when the optimized parameters for the DSI are used for future applications. It seems more robust than steady-state or long-term spin-up runs which rely on strong assumptions. Further tests are needed before using the DSI for mineralogy that differs considerably from the soils of this study.

\subsection{Parameter uncertainty as estimated with Bayesian calibration}

According to our Bayesian calibrations, a wide range of parameter values are possible for Daisy, going far beyond the initial published parameter sets. By combining various sites and including meaningful proxies, such as the DSI, the parameter uncertainty and equifinality could be reduced and the credibility intervals narrowed. The predictions of mechanistic models usually fail to account for the three main statistical uncertainties in (1) inputs, (2) scientific judgments resulting in different model setups and (3) driving data (Wattenbach et al., 2006). However, with a Bayesian calibration framework such as that implemented in UCODE 2014, almost any model can be made probabilistic, so uncertainties in parameters and outputs can be assessed, even for projections into the future (Clifford et al., 2014). As this study focused on Bayesian calibration and we used an established model, we mainly address parameter uncertainty, although input uncertainty was also included through the weighting process. We clearly demonstrated an effect of the individual site used for Bayesian calibration on the resulting model parameters and uncertainties. Similarly diverging site-specific turnover rates 
were also found by Ahrens et al. (2014) in a study of soil carbon in forests. Diverging results for different sites generally point towards a need for a better understanding of the modeled system and model improvements (Poeter et al., 2005), but this often requires a deeper understanding of the system and new measurements - hence it is not always feasible. A Bayesian calibration asks the following question: what would be the probability distribution of parameters, given that the measured data should be represented by the selected model? Hence, if only one site is used, it can only answer this question for that specific site. As this study showed, the parameter set could then be highly biased for other sites. For a more robust calibration, several sites should be combined to obtain posterior distributions of parameters for a gradient of sites, though this might reduce model performance for individual sites. The introduction of the equal weighting scheme, which gave similar weights to the different sites, highlights how much bias may be introduced by user decisions of artificial weighting: this Bayesian calibration parameter set had the highest uncertainties, and it appears as if the Ultuna site had by far the strongest influence. In contrast to that, the combination of all four sites with the original weights based on the error variances or measurements led to a very clear reduction in parameter uncertainty and the narrowest parameter credibility intervals (Fig. 6a compared to Fig. 6b and c).

The results of the statistical analysis of model errors (Table 4) suggest that the DSI is suitable for SOC model pool initialization. This was corroborated by the Bayesian calibration, as the inclusion of the DSI narrowed credibility intervals for the slow SOM pool turnover and humification efficiency and reduced the correlation between fast and slow SOM turnover compared to the simulation without the DSI as a constraint. Especially in the case of the clear differentiation between $k_{\text {SOM_slow }}$ and $k_{\text {SOM_fast }}$, our results show the advantage of attaching a physiochemical meaning to the pools that was not provided before. Other effective approaches, such as using time series of ${ }^{14} \mathrm{C}$ data, could be combined with the DSI for better results.

Of all three parameters, the humification efficiency ( $\left.f_{\text {SOM_slow }}\right)$ was the only parameter that consistently ran into the upper boundaries, set to $35 \%$. In fact, initial calibrations were carried out where $f_{\text {SOM slow }}$ was constrained to $95 \%$; even then, it tended to run into that constraint (Fig. S8) and led to much faster turnover rates $\left(k_{\text {SOM_slow }}\right)$ than were published before. These values of $f_{\text {SOM_slow }}$ were much greater than the $10 \%$ for the Mueller et al. (1997) dataset, $30 \%$ for Bruun et al. (2003) and other published two-pool models. Therefore, we considered the cause of the poorly constrained $f_{\text {SOM_slow }}$ parameter to be a model formulation problem, which did not depend on whether the DSI was included in the Bayesian calibration or not. Only when the humification efficiency was restricted in the Bayesian calibration did the turnover of fast and slow SOM align with the earlier published rates. If a parameter is problematic, such as $f_{\text {SOM_slow }}$, it could mean that there are a lack of data. However, if pa- rameters are constrained but run into implausible values, it usually means that the model structure is suboptimal (Poeter et al., 2005) and should be altered.

\subsection{Model structure determines SOM turnover times in two-pool models}

The rate of SOM decomposition remains of major interest, especially with respect to the potential of SOM as a global carbon sink (Minasny et al., 2017). Some of the first conceptual approaches proposed SOM pools with residence times of 1000 years and longer (e.g., in CENTURY, Parton et al., 1987), but the SOM models were calibrated to fit data measured in long-term experiments that included vegetation. The pool structure of early SOM models such as Daisy and CENTURY were rather similar as were the turnover rates of SOM pools (see summary in Table 5). An improved understanding of the actual number of carbon inputs to the soil, which remains challenging to measure, led to faster turnover rates in more recent model versions (e.g., by Bruun et al., 2003). The reason is probably that inputs of carbon and nitrogen to the soil were initially underestimated as it is very difficult to measure root turnover and rhizosphere exudation inputs without expensive in situ ${ }^{13} \mathrm{C}$ or ${ }^{14} \mathrm{C}$ labeling. The underestimated inputs were then likely counterbalanced in the model calibration by slower turnover rates resulting in acceptable model outputs ( $\mathrm{SOM}$ dynamics and $\mathrm{CO}_{2}$ emissions) for the time being. However, as our summary of more recent studies underlines (Table 5), the earlier published turnover rates seem to be subject to a systematic underestimation. As the comparison of our Bayesian calibration to other recent Bayesian calibration studies suggests, the relatively fast turnover rates of this study are in alignment with other recent findings (Table 5), as all five examples have published turnover rates for the slow SOM pool, which are at least 1 order of magnitude faster than early assumptions from the 1980s and 1990s.

It is critical to understand model uncertainties and to test fundamental assumptions of how SOM is transferred between the pools (Sulman et al., 2018). The comparison between constrained and unconstrained humification efficiency in the Bayesian calibrations suggests that the sequential flow of carbon through the system might be assuming a condensation of stabile carbon that does not actually explain the vast majority of more stable SOM formation. From a theoretical perspective, one may wonder how large amounts of less complex SOM should become complex SOM without any involvement of living soil organisms. The way that the formation of complex carbon is represented in Daisy is probably a remainder of earlier humification theories from the 1990s that mostly ignored microbe involvement, while most of the recent studies suggest that the vast majority of SOM is of microbial origin (Cotrufo et al., 2013). A simple adaption for two-pool SOM models such as Daisy that include SMB pools could acknowledge this paradigm shift: the parti- 
Table 5. Optimized turnover rates and humification efficiency of this study (using the combined site analysis with original weighting and the DSI) compared to other Bayesian calibrations and standard values of commonly used models. Turnover rates of other models were normalized to the Daisy standard of $10^{\circ} \mathrm{C}$ using an exponential equation (an exception was Clifford et al., 2014, where no temperature was given).

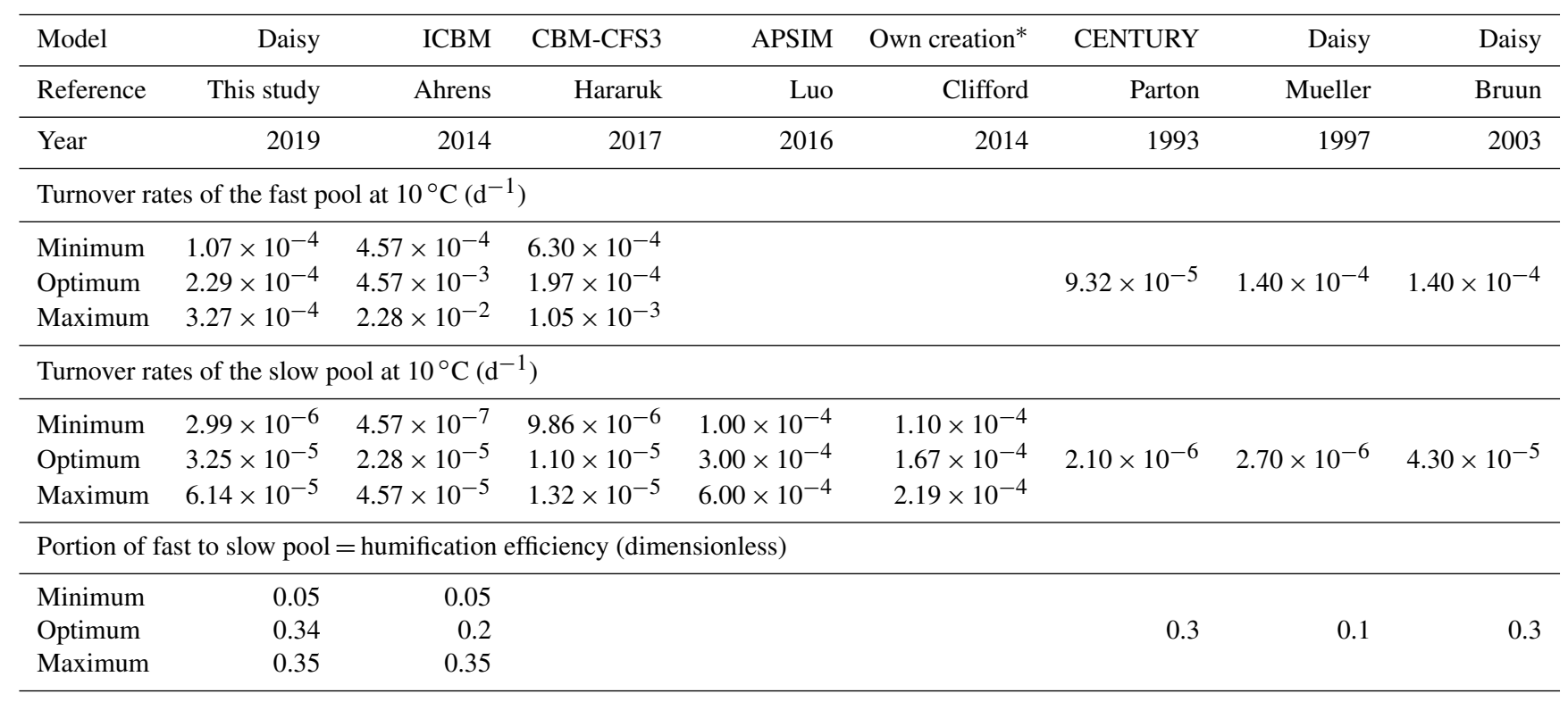

References: Ahrens et al. (2014), Bruun et al. (2003), Clifford et al. (2014), Hararuk et al. (2017), Luo et al. (2016), Mueller et al. (1997) and Parton et al. (1993). * Clifford et al. (2014) did not specify a base temperature for their model.

tioning between slow- and fast-turnover SOM could be at the death of the microbial biomass (Fig. 7) without any transfer of SOM from fast to slow pools (a brief test of this new structure is provided in Fig. S10). This would also be in alignment with the DSI concept, as aliphatic carbon should not spontaneously transform to aromatic-carboxylate carbon on its own. Then Daisy would fit better to the DSI and other proxies linking measurable fractions to SOM pools (the same is true for CENTURY and other models, which apply the same humification principle). The way that pools are linked in the current model configuration is such that the actual turnover time of recalcitrant SOM consists of the turnover of the fast and slow SOM pools combined as it moves through these pools sequentially (Fig. 1).

How strongly the basic model assumptions influence SOM simulations is also reflected when differences between oneand two-pool SOM models are compared. The turnover rates of the one-pool models are in between those of slow and fast SOM pools. However, our comparison shows that models with similar structure come to similar conclusions for SOM turnover. For example, the one-pool model in Clifford et al. (2014) was quite similar in turnover rates to that in Luo et al. (2016) but does not match well with two-pool models. Then again, the rates for the two-pool models of this study, and the studies by Ahrens et al. (2014) and Hararuk et al. (2017), were very similar in their minima and maxima, for both the slow and fast SOM pools, which shows that only models with a similar number of pools and transformations could be compared.

The $95 \%$ credibility intervals of half-lives in Daisy were in the range from 278 to 1095 years for the slow SOM pool and from 47 to 90 years for the fast SOM pool for the combination of sites presented in this study. If these values were reasonable - and as the three recently published Bayesian calibrations including this study are quite close in turnover rates (Table 5), this seems to be the case - SOM could be lost at much faster rates under mismanagement and global warming than earlier modeling results suggest. The rates may also be biased towards an underestimation of turnover, as even with intense efforts it is next to impossible to keep bare fallow plots completely free of vegetation (weeds) and roots from neighboring plots. Recent studies are in alignment with the possibility of relatively fast SOC loss across various scales from field scale (Poyda et al., 2019) to country scale. For example in Germany, agricultural soils are much more often a carbon source than a sink (Jacobs et al., 2018). This highlights the importance of adequate SOM management and a deeper understanding of the processes at different scales. Especially in the context of understanding the response of SOM to climate change, it is not enough if the SOM balance is simulated appropriately, but fluxes within the plant-soil system also need to be quantified. The reason is that under a warmer climate and changing soil moisture levels, the plant-derived carbon inputs will change. Furthermore, soil enzymatic analysis at regional and field lev- 


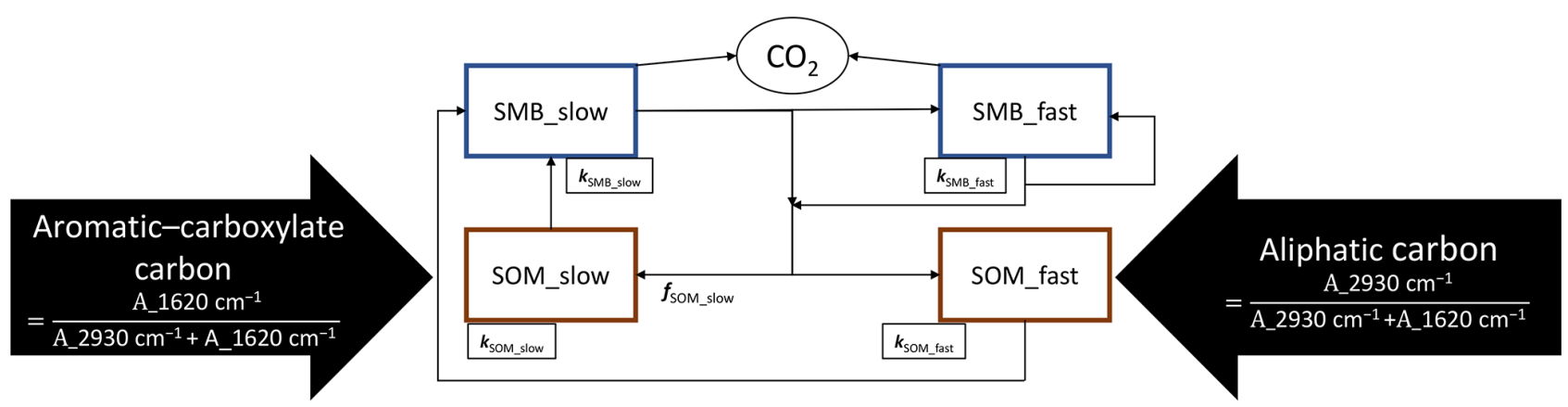

Figure 7. Suggested improvements to the internal cycling structure of SOM in the Daisy model. The division into fast- and slow-cycling SOM, corresponding to aliphatic and aromatic-carboxylate carbon follows the turnover or death of either SMB pool. Aliphatic carbon no longer becomes aromatic-carboxylate carbon without the involvement of microbes.

els (Ali et al., 2015, 2018) suggest that pools of different complexity have different temperature sensitivities (Lefèvre et al., 2014), which is also realized in new models (Hararuk et al., 2017). If different pools have different responses to temperature, the formula by Bruun and Jensen (2002) for SOM pool distribution could not be used anymore, as it implicitly assumes a similar temperature sensitivity for all pools. In light of this, new proxies such as the DSI, soil fractionation or ${ }^{14} \mathrm{C}$ use (Menichetti et al., 2016), which could also be combined, are crucial for making SOM pools chemically or physically meaningful and for reducing model uncertainty and equifinality. As the DSI also had a good correlation with structurally protected SOM (Demyan et al., 2012), it could also fit very well to models that directly simulate the protection of SOM as a function of microbial activity (Sulman et al., 2014). A better understanding and the use of meaningful proxies such as DRIFTS, pyrolysis with DRIFTS (Nkwain et al., 2018) or thermal deconvolution (Cécillon et al., 2018; Demyan et al., 2013) in combination with Bayesian calibration and a wide range of long-term experiments are needed. The discrepancy between simulating SOM of tropical and temperate soils, which points towards a lack of understanding of fundamental differences in processes at work on the global scale would be the best test for future proxies and SOM models, which should be facilitated by freely available datasets for model testing and calibration.

\section{Conclusions}

We tested the use of the DRIFTS stability index as a proxy for initializing the two SOM pools in the Daisy model and used a Bayesian calibration to implement this proxy. A statistical analysis of model errors suggested that the use of the DRIFTS stability index to initialize the fast and slow SOM pools significantly reduced model errors in most cases, especially those with initially poor performance. The DSI therefore seems to be a robust proxy for distinguishing between fast- and slow-cycling SOM in order to initialize two-pool models and adds physicochemical meaning to the pools. As other studies have also shown, statistically sound approaches such as Bayesian calibration are needed to grasp the high uncertainty in SOM turnover, which is often neglected in modeling exercises. The results of the Bayesian optimization procedure further suggest that model performance could be improved by adjusting model parameters (turnover rates, humification efficiency) in the DSI initialization approach. Meaningful proxies such as DRIFTS, physical and chemical fractionation, or ${ }^{14} \mathrm{C}$ age assessments are likely to be the most robust way to initialize SOM pools, but their measurement method needs to be optimized to overcome known constraints, such as water and mineral interference in the case of the DSI. The results of this study suggest that the turnover of SOM could be much faster than assumed by commonly used SOM models. For example, the Daisy slow SOM pool half-life estimated in our study ranged from 278 to 1095 years (95\% credibility intervals). The variability in parameters highlights the importance of including meaningful proxies in SOM models and conducting research on a larger gradient of soils with bare fallow and planted sites and over longer time frames.

Data availability. Data of SOC from Ultuna and Bad Lauchstädt have already been published in the last few decades and are cited in the text. The data of Kraichgau and Swabian Jura have not been published yet but are provided in the graphs. The raw data which were used in this study are available in the Supplement of this article.

Supplement. The supplement related to this article is available online at: https://doi.org/10.5194/bg-17-1393-2020-supplement.

Author contributions. MSD and GC designed the Kraichgau and Swabian Jura field experiments and had the initial idea of using the DSI in modeling. TK provided the samples from Ultuna. MSD, YFN and ML conducted field samplings and measurements. ML 
conducted the modeling and Bayesian calibration. HPP provided several of the main ideas for statistics (Sect. 2.4 and 2.5). ML and SB wrote the original draft. All authors contributed towards developing the final paper from the original draft.

Competing interests. The authors declare that they have no conflict of interest.

Acknowledgements. This research was supported by the German Research Foundation (DFG) under the projects PAK 346 and the following research unit, FOR1695 Agricultural Landscapes under Global Climate Change - Processes and Feedbacks on a Regional Scale, within subproject P3. We would like to thank Elke Schulz from the Department of Soil Ecology, Helmholtz Centre for Environmental Research in Halle (Saale), for the provision of samples from Bad Lauchstädt. We would also like to thank Steffen Mehl, from the UCODE development team, for his help with the weighing of observations and the troubleshooting during the setup of UCODE_2014 on the bwUniCluster. Finally, we thank the editor and all the reviewers, especially Lauric Cécillon, for the fruitful discussions during the review process. The authors acknowledge support by the state of Baden-Württemberg through the bwHPC project.

Financial support. This research has been supported by the German Research Foundation (DFG; grant nos. CA 598/6-1 and 6-2).

Review statement. This paper was edited by Michael Weintraub and reviewed by Sander Bruun, Lauric Cécillon and two anonymous referees.

\section{References}

Abramoff, R., Xu, X., Hartman, M., O’Brien, S., Feng, W., Davidson, E., Finzi, A., Moorhead, D., Schimel, J., Torn, M., and Mayes, M. A.: The Millennial model: in search of measurable pools and transformations for modeling soil carbon in the new century, Biogeochemistry, 137, 51-71, https://doi.org/10.1007/s10533-017-0409-7, 2018.

Ahrens, B., Reichstein, M., Borken, W., Muhr, J., Trumbore, S. E., and Wutzler, T.: Bayesian calibration of a soil organic carbon model using $\Delta^{14} \mathrm{C}$ measurements of soil organic carbon and heterotrophic respiration as joint constraints, Biogeosciences, 11, 2147-2168, https://doi.org/10.5194/bg-11-2147-2014, 2014.

Ali, R. S., Ingwersen, J., Demyan, M. S., Funkuin, Y. N., Wizemann, H.-D., Kandeler, E., and Poll, C.: Modelling in situ activities of enzymes as a tool to explain seasonal variation of soil respiration from agro-ecosystems, Soil Biol. Biochem., 81, 291303, https://doi.org/10.1016/j.soilbio.2014.12.001, 2015.

Ali, R. S., Kandeler, E., Marhan, S., Demyan, M. S., Ingwersen, J., Mirzaeitalarposhti, R., Rasche, F., Cadisch, G., and Poll, C.: Controls on microbially regulated soil organic carbon decom- position at the regional scale, Soil Biol. Biochem., 118, 59-68, https://doi.org/10.1016/j.soilbio.2017.12.007, 2018.

Andrén, O. and Kätterer, T.: ICBM: The introductory carbon balance model for exploration of soil carbon balances, Ecol. Appl., 7, 1226-1236, https://doi.org/10.1890/10510761(1997)007[1226:ITICBM]2.0.CO;2, 1997.

Bailey, V. L., Bond-Lamberty, B., DeAngelis, K., Grandy, A. S., Hawkes, C. V., Heckman, K., Lajtha, K., Phillips, R. P., Sulman, B. N., Todd-Brown, K. E. O., and Wallenstein, M. D.: Soil carbon cycling proxies: Understanding their critical role in predicting climate change feedbacks, Glob. Change Biol., 24, 895-905, https://doi.org/10.1111/gcb.13926, 2018.

Barré, P., Plante, A. F., Cécillon, L., Lutfalla, S., Baudin, F., Bernard, S., Christensen, B. T., Eglin, T., Fernandez, J. M., Houot, S., Kätterer, T., Le Guillou, C., Macdonald, A., van Oort, F., and Chenu, C.: The energetic and chemical signatures of persistent soil organic matter, Biogeochemistry, 130, 1-12, https://doi.org/10.1007/s10533-016-0246-0, 2016.

Blair, N., Faulkner, R. D., Till, A. R., Korschens, M., and Schulz, E.: Long-term management impacts on soil C, N and physical fertility. Part II: Bad Lauchstadt static and extreme FYM experiments, Soil Till. Res., 91, 39-47, https://doi.org/10.1016/j.still.2005.11.001, 2006.

Bruun, S. and Jensen, L. S.: Initialisation of the soil organic matter pools of the Daisy model, Ecol. Modell., 153, 291-295, https://doi.org/10.17665/1676-4285.20155108, 2002.

Bruun, S., Christensen, B. T., Hansen, E. M., Magid, J., and Jensen, L. S.: Calibration and validation of the soil organic matter dynamics of the Daisy model with data from the Askov long-term experiments, Soil Biol. Biochem., 35, 67-76, https://doi.org/10.1016/S0038-0717(02)00237-7, 2003.

Calderón, F. J., Reeves, J. B., Collins, H. P., and Paul, E. A.: Chemical Differences in Soil Organic Matter Fractions Determined by Diffuse-Reflectance Mid-Infrared Spectroscopy, Soil Sci. Soc. Am. J., 75, 568-579, https://doi.org/10.2136/sssaj2009.0375, 2011.

Campbell, E. E. E. and Paustian, K.: Current developments in soil organic matter modeling and the expansion of model applications: a review, Environ. Res. Lett., 10, 123004, https://doi.org/10.1088/1748-9326/10/12/123004, 2015.

Cécillon, L., Baudin, F., Chenu, C., Houot, S., Jolivet, R., Kätterer, T., Lutfalla, S., Macdonald, A., van Oort, F., Plante, A. F., Savignac, F., Soucémarianadin, L. N., and Barré, P.: A model based on Rock-Eval thermal analysis to quantify the size of the centennially persistent organic carbon pool in temperate soils, Biogeosciences, 15, 2835-2849, https://doi.org/10.5194/bg-152835-2018, 2018.

Clifford, D., Pagendam, D., Baldock, J., Cressie, N., Farquharson, R., Farrell, M., Macdonald, L., and Murray, L.: Rethinking soil carbon modelling: a stochastic approach to quantify uncertainties, Environmetrics, 25, 265-278, https://doi.org/10.1002/env.2271, 2014.

Coleman, K. and Jenkinson, D. S.: RothC-26.3 - A Model for the turnover of carbon in soil, in Evaluation of Soil Organic Matter Models, Springer Berlin Heidelberg, Berlin, Heidelberg, 237246, 1996.

Cotrufo, M. F., Wallenstein, M. D., Boot, C. M., Denef, K., and Paul, E.: The Microbial Efficiency-Matrix Stabilization (MEMS) framework integrates plant litter decomposition with 
soil organic matter stabilization: do labile plant inputs form stable soil organic matter?, Glob. Change Biol., 19, 988-995, https://doi.org/10.1111/gcb.12113, 2013.

Demyan, M. S., Rasche, F., Schulz, E., Breulmann, M., Müller, T., and Cadisch, G.: Use of specific peaks obtained by diffuse reflectance Fourier transform mid-infrared spectroscopy to study the composition of organic matter in a Haplic Chernozem, Eur. J. Soil Sci., 63, 189-199, https://doi.org/10.1111/j.13652389.2011.01420.x, 2012.

Demyan, M. S., Rasche, F., Schütt, M., Smirnova, N., Schulz, E., and Cadisch, G.: Combining a coupled FTIR-EGA system and in situ DRIFTS for studying soil organic matter in arable soils, Biogeosciences, 10, 2897-2913, https://doi.org/10.5194/bg-102897-2013, 2013.

Ellerbrock, R. H. and Gerke, H. H.: Explaining soil organic matter composition based on associations between $\mathrm{OM}$ and polyvalent cations, J. Plant Nutr. Soil Sci., 181, 721-736, https://doi.org/10.1002/jpln.201800093, 2018.

Franko, U. and Merbach, I.: Modelling soil organic matter dynamics on a bare fallow Chernozem soil in Central Germany, Geoderma, 303, 93-98, https://doi.org/10.1016/j.geoderma.2017.05.013, 2017.

Gelman, A. and Rubin, D. B.: Inference from Iterative Simulation Using Multiple Sequences, Stat. Sci., 7, 457-472, https://doi.org/10.1214/ss/1177011136, 1992.

Giacometti, C., Demyan, M. S., Cavani, L., Marzadori, C., Ciavatta, C., and Kandeler, E.: Chemical and microbiological soil quality indicators and their potential to differentiate fertilization regimes in temperate agroecosystems, Appl. Soil Ecol., 64, 3248, https://doi.org/10.1016/j.apsoil.2012.10.002, 2013.

Good, W. D. and Smith, N. K.: Enthalpies of combustion of toluene, benzene, cyclohexane, cyclohexene, methylcyclopentane, 1-methylcyclopentene, and n-hexane, J. Chem. Eng. Data, 14, 102-106, https://doi.org/10.1021/je60040a036, 1969.

Hansen, S., Jensen, L. S., Nielsen, N. E., and Svendsen, H.: The Soil Plant System Model Daisy - Basic Principles and Modelling Approach, The Royal Veterinary and Agricultural University, Copenhagen, 39-50, 1993.

Hansen, S., Abrahamsen, P., Petersen, C. T., and Styczen, M.: Daisy: Model Use, Calibration, and Validation, Trans. ASABE, 55, 1317-1335, https://doi.org/10.13031/2013.42244, 2012.

Hararuk, O., Shaw, C., and Kurz, W. A.: Constraining the organic matter decay parameters in the CBM-CFS3 using Canadian National Forest Inventory data and a Bayesian inversion technique, Ecol. Modell., 364, 1-12, https://doi.org/10.1016/j.ecolmodel.2017.09.008, 2017.

Heinlein, F., Biernath, C., Klein, C., Thieme, C., and Priesack, E.: Evaluation of Simulated Transpiration from Maize Plants on Lysimeters, Vadose Zone J., 16, 1-16, https://doi.org/10.2136/vzj2016.05.0042, 2017.

Herbst, M., Welp, G., Macdonald, A., Jate, M., Hädicke, A., Scherer, H., Gaiser, T., Herrmann, F., Amelung, W., and Vanderborght, J.: Correspondence of measured soil carbon fractions and RothC pools for equilibrium and non-equilibrium states, Geoderma, 314, 37-46, https://doi.org/10.1016/j.geoderma.2017.10.047, 2018.

Jacobs, A., Flessa, H., Don, A., Heidkamp, A., Prietz, R., Dechow, R., Gensior, A., Poeplau, C., Riggers, C., Schneider, F., Tiemeyer, B., Vos, C., Wittnebel, M., Müller, T., Säurich, A.,
Fahrion-Nitschke, A., Gebbert, S., Hopfstock, R., Jaconi, A., Kolata, H., Lorbeer, M., Schröder, J., Laggner, A., Weiser, C., and Freibauer, A.: Landwirtschaftlich genutzte Böden in Deutschland - Ergebnisse der Bodenzustandserhebung - Thünen Report 64, Johann Heinrich von Thünen-Institut, Bundesallee 50, 38116 Braunschweig, Germany, 2018.

Jensen, L. S., Mueller, T., Nielsen, N. E., Hansen, S., Crocker, G. J., Grace, P. R., Klír, J., Körschens, M., and Poulton, P. R.: Simulating trends in soil organic carbon in long-term experiments using the soil-plant-atmosphere model DAISY, Geoderma, 81, 5-28, https://doi.org/10.1016/S0016-7061(97)88181-5, 1997.

Joergensen, R. G. and Mueller, T.: The fumigation-extraction method to estimate soil microbial biomass: Calibration of the kEC value, Soil Biol. Biochem., 28, 25-31, https://doi.org/10.1016/0038-0717(95)00102-6, 1996.

Kätterer, T., Bolinder, M. A., Andrén, O., Kirchmann, H., and Menichetti, L.: Roots contribute more to refractory soil organic matter than above-ground crop residues, as revealed by a longterm field experiment, Agr. Ecosyst. Environ., 141, 184-192, https://doi.org/10.1016/j.agee.2011.02.029, 2011.

Kirchmann, H., Haberhauer, G., Kandeler, E., Sessitsch, A., and Gerzabek, M. H.: Effects of level and quality of organic matter input on carbon storage and biological activity in soil: Synthesis of a long-term experiment, Global Biogeochem. Cy., 18, 1-9, https://doi.org/10.1029/2003GB002204, 2004.

Klein, C., Biernath, C., Heinlein, F., Thieme, C., Gilgen, A. K., Zeeman, M., and Priesack, E.: Vegetation Growth Models Improve Surface Layer Flux Simulations of a Temperate Grassland, Vadose Zone J., 16, 1-19, https://doi.org/10.2136/vzj2017.03.0052, 2017.

Klein, C. G.: Modeling fluxes of energy and water between land surface and atmosphere for grass- and cropland system, Fakultät Wissenschaftszentrum Weihenstephan, 11-20, 2018.

Kozak, M. and Piepho, H. P.: What's normal anyway? Residual plots are more telling than significance tests when checking ANOVA assumptions, J. Agron. Crop Sci., 204, 86-98, https://doi.org/10.1111/jac.12220, 2018.

Laub, M., Blagodatsky, S., Nkwain, Y. F., and Cadisch, G.: Soil sample drying temperature affects specific organic midDRIFTS peaks and quality indices, Geoderma, 355, 113897, https://doi.org/10.1016/j.geoderma.2019.113897, 2019.

Lefèvre, R., Barré, P., Moyano, F. E., Christensen, B. T., Bardoux, G., Eglin, T., Girardin, C., Houot, S., Kätterer, T., van Oort, F., and Chenu, C.: Higher temperature sensitivity for stable than for labile soil organic carbon - Evidence from incubations of long-term bare fallow soils, Glob. Change Biol., 20, 633-640, https://doi.org/10.1111/gcb.12402, 2014.

Lu, D., Ye, M., and Hill, M. C.: Analysis of regression confidence intervals and Bayesian credible intervals for uncertainty quantification, Water Resour. Res., 48, 1-20, https://doi.org/10.1029/2011WR011289, 2012.

Lu, D., Ye, M., Hill, M. C., Poeter, E. P., and Curtis, G. P.: A computer program for uncertainty analysis integrating regression and Bayesian methods, Environ. Model. Softw., 60, 45-56, https://doi.org/10.1016/j.envsoft.2014.06.002, 2014.

Luo, Z., Wang, E., Shao, Q., Conyers, M. K., and Liu, D. L.: Confidence in soil carbon predictions undermined by the uncertainties in observations and model parameterisation, Environ. Model. 
Softw., 80, 26-32, https://doi.org/10.1016/j.envsoft.2016.02.013, 2016.

Margenot, A. J., Calderón, F. J., Bowles, T. M., Parikh, S. J., and Jackson, L. E.: Soil Organic Matter Functional Group Composition in Relation to Organic Carbon, Nitrogen, and Phosphorus Fractions in Organically Managed Tomato Fields, Soil Sci. Soc. Am. J., 79, 772-782, https://doi.org/10.2136/sssaj2015.02.0070, 2015.

Menichetti, L., Kätterer, T., and Leifeld, J.: Parametrization consequences of constraining soil organic matter models by total carbon and radiocarbon using long-term field data, Biogeosciences, 13, 3003-3019, https://doi.org/10.5194/bg-13-3003-2016, 2016.

Minasny, B., Malone, B. P., McBratney, A. B., Angers, D. A., Arrouays, D., Chambers, A., Chaplot, V., Chen, Z.-S., Cheng, K., Das, B. S., Field, D. J., Gimona, A., Hedley, C. B., Hong, S. Y., Mandal, B., Marchant, B. P., Martin, M., McConkey, B. G., Mulder, V. L., O'Rourke, S., Richer-deForges, A. C., Odeh, I., Padarian, J., Paustian, K., Pan, G., Poggio, L., Savin, I., Stolbovoy, V., Stockmann, U., Sulaeman, Y., Tsui, C.-C., Vågen, T.-G., van Wesemael, B., and Winowiecki, L.: Soil carbon 4 per mille, Geoderma, 292, 59-86, https://doi.org/10.1016/j.geoderma.2017.01.002, 2017. .

Monteith, J. L.: Evaporation and surface temperature, Q. J. R. Meteorol. Soc., 12, 513-522, https://doi.org/10.1002/qj.49710745102, 1976.

Mualem, Y.: A new model for predicting the hydraulic conductivity of unsaturated porous media, Water Resour. Res., 12, 513-522, https://doi.org/10.1029/WR012i003p00513, 1976.

Mueller, T., Jensen, L. S. S., Magid, J., and Nielsen, N. E. E.: Temporal variation of $\mathrm{C}$ and $\mathrm{N}$ turnover in soil after oilseed rape straw incorporation in the field: simulations with the soilplant-atmosphere model DAISY, Ecol. Modell., 99, 247-262, https://doi.org/10.1016/S0304-3800(97)01959-5, 1997.

Mueller, T., Magid, J., Jensen, L. S., Svendsen, H., and Nielsen, N. E.: Soil $\mathrm{C}$ and $\mathrm{N}$ turnover after incorporation of chopped maize, barley straw and blue grass in the field: Evaluation of the DAISY soil-organic-matter submodel, Ecol. Modell., 111, 1-15, https://doi.org/10.1016/S0304-3800(98)00094-5, 1998.

Nguyen, T., Janik, L., and Raupach, M.: Diffuse reflectance infrared fourier transform (DRIFT) spectroscopy in soil studies, Soil Res., 29, 49-67, https://doi.org/10.1071/SR9910049, 1991.

Nkwain, F. N., Demyan, M. S., Rasche, F., Dignac, M.-F., Schulz, E., Kätterer, T., Müller, T., and Cadisch, G.: Coupling pyrolysis with mid-infrared spectroscopy (Py-MIRS) to fingerprint soil organic matter bulk chemistry, J. Anal. Appl. Pyrol., 133, 176-184, https://doi.org/10.1016/j.jaap.2018.04.004, 2018.

Nocita, M., Stevens, A., van Wesemael, B., Aitkenhead, M., Bachmann, M., Barthès, B., Ben Dor, E., Brown, D. J., Clairotte, M., Csorba, A., Dardenne, P., Demattê, J. A. M., Genot, V., Guerrero, C., Knadel, M., Montanarella, L., Noon, C., Ramirez-Lopez, L., Robertson, J., Sakai, H., Soriano-Disla, J. M., Shepherd, K. D., Stenberg, B., Towett, E. K., Vargas, R., and Wetterlind, J.: Soil Spectroscopy: An Alternative to Wet Chemistry for Soil Monitoring, Adv. Agron., 132, 139-159, 2015.

O'Leary, G. J., Liu, D. L., Ma, Y., Li, F. Y., McCaskill, M., Conyers, M., Dalal, R., Reeves, S., Page, K., Dang, Y. P., and Robertson, F.: Modelling soil organic carbon 1. Performance of APSIM crop and pasture modules against long-term experimental data, Geoderma, 264, 227-237, https://doi.org/10.1016/j.geoderma.2015.11.004, 2016.

Parton, W. J., Schimel, D. S., Cole, C. V., and Ojima, D. S.: Analysis of Factors Controlling Soil Organic Matter Levels in Great Plains Grasslands1, Soil Sci. Soc. Am. J., 51, 1173, https://doi.org/10.2136/sssaj1987.03615995005100050015x, 1987.

Parton, W. J., Scurlock, J. M. O., Ojima, D. S., Gilmanov, T. G., Scholes, R. J., Schimel, D. S., Kirchner, T., Menaut, J.-C., Seastedt, T., Garcia Moya, E., Kamnalrut, A., and Kinyamario, J. I.: Observations and modeling of biomass and soil organic matter dynamics for the grassland biome worldwide, Global Biogeochem. Cy., 7, 785-809, https://doi.org/10.1029/93GB02042, 1993.

Pengerud, A., Cécillon, L., Johnsen, L. K., Rasse, D. P., and Strand, L. T.: Permafrost Distribution Drives Soil Organic Matter Stability in a Subarctic Palsa Peatland, Ecosystems, 16, 934-947, https://doi.org/10.1007/s10021-013-9652-5, 2013.

Piepho, H. P., Büchse, A., and Richter, C.: A Mixed Modelling Approach for Randomized Experiments with Repeated Measures, J. Agron. Crop Sci., 190, 230-247, https://doi.org/10.1111/j.1439037X.2004.00097.x, 2004.

Poeplau, C., Don, A., Dondini, M., Leifeld, J., Nemo, R., Schumacher, J., Senapati, N., and Wiesmeier, M.: Reproducibility of a soil organic carbon fractionation method to derive RothC carbon pools, Eur. J. Soil Sci., 64, 735-746, https://doi.org/10.1111/ejss.12088, 2013.

Poeter, E. P., Hill, M. C., Banta, E. R., Mehl, S., and Christensen, S.: UCODE_2005 and six other computer codes for universal sensitivity analysis, inverse modeling, and uncertainty evaluation, U.S. Geological Survey Techniques and Methods 6-A11, 283 pp., 2005 (updated in February 2008).

Poeter, E. P., Hill, M. C., Lu, D., Tiedeman, C. R., and Mehl, S.: UCODE_2014, with New Capabilities to Define Parameters Unique to Predictions, Calculate Weights using Simulated Values, Estimate Parameters with SVD, Evaluate Uncertainty with MCMC, and More, Integrated Groundwater Modeling Center Report Number: GWMI 2014-02, 2014.

Poyda, A., Wizemann, H.-D., Ingwersen, J., Eshonkulov, R., Högy, P., Demyan, M. S., Kremer, P., Wulfmeyer, V., and Streck, T.: Carbon fluxes and budgets of intensive crop rotations in two regional climates of southwest Germany, Agr. Ecosyst. Environ., 276, 31-46, https://doi.org/10.1016/j.agee.2019.02.011, 2019.

Segoli, M., De Gryze, S., Dou, F., Lee, J., Post, W. M., Denef, K., and Six, J.: AggModel: A soil organic matter model with measurable pools for use in incubation studies, Ecol. Modell., 263, 1-9, https://doi.org/10.1016/j.ecolmodel.2013.04.010, 2013.

Sohi, S. P., Mahieu, N., Arah, J. R. M., Powlson, D. S., Madari, B., and Gaunt, J. L.: A Procedure for Isolating Soil Organic Matter Fractions Suitable for Modeling, Soil Sci. Soc. Am. J., 65, 1121, https://doi.org/10.2136/sssaj2001.6541121x, 2001.

Stevenson, F. J.: Humus chemistry: genesis, composition, reactions, John Wiley \& Sons, New York, 308-317, 1994.

Sulman, B. N., Phillips, R. P., Oishi, A. C., Shevliakova, E., and Pacala, S. W.: Microbe-driven turnover offsets mineral-mediated storage of soil carbon under elevated $\mathrm{CO}_{2}$, Nat. Clim. Change, 4 , 1099-1102, https://doi.org/10.1038/nclimate2436, 2014.

Sulman, B. N., Moore, J. A. M., Abramoff, R., Averill, C., Kivlin, S., Georgiou, K., Sridhar, B., Hartman, M. D., Wang, G., Wieder, W. R., Bradford, M. A., Luo, Y., Mayes, M. A., Morrison, E., 
Riley, W. J., Salazar, A., Schimel, J. P., Tang, J., and Classen, A. T.: Multiple models and experiments underscore large uncertainty in soil carbon dynamics, Biogeochemistry, 141, 109-123, https://doi.org/10.1007/s10533-018-0509-z, 2018.

Tinti, A., Tugnoli, V., Bonora, S., and Francioso, O.: Recent applications of vibrational mid-infrared (IR) spectroscopy for studying soil components: A review, J. Cent. Eur. Agric., 16, 1-22, https://doi.org/10.5513/JCEA01/16.1.1535, 2015.

van Genuchten, M. T.: A comparison of numerical solutions of the one-dimensional unsaturated - saturated flow and mass transport equations, Adv. Water Resour., 5, 47-55, https://doi.org/10.1016/0309-1708(82)90028-8, 1982.

Vrugt, J. A.: Markov chain Monte Carlo simulation using the DREAM software package: Theory, concepts, and MATLAB implementation, Environ. Model. Softw., 75, 273-316, https://doi.org/10.1016/j.envsoft.2015.08.013, 2016.

Wattenbach, M., Gottschalk, P., Hatterman, C., Rachimow, C., Flechsig, M., and Smith, P.: A framework for assessing uncertainty in ecosystem models, in Proceedings of the iEMSs Third Biennial Meeting, Paper 373, International Environmental Modeling and Software Society, available at: https://abdn.pure.elsevier.com/en/publications/ a-framework-for-assessing-uncertainty-in-ecosystem-models (last access: 17 March 2020), 2006.
Wizemann, H.-D., Ingwersen, J., Högy, P., Warrach-Sagi, K., Streck, T., and Wulfmeyer, V.: Three year observations of water vapor and energy fluxes over agricultural crops in two regional climates of Southwest Germany, Meteorol. Zeitschrift, 24, 3959, https://doi.org/10.1127/metz/2014/0618, 2015.

Yeasmin, S., Singh, B., Johnston, C. T., and Sparks, D. L.: Evaluation of pre-treatment procedures for improved interpretation of mid infrared spectra of soil organic matter, Geoderma, 304, 8392, https://doi.org/10.1016/j.geoderma.2016.04.008, 2017.

Zimmermann, M., Leifeld, J., Schmidt, M. W. I., Smith, P., and Fuhrer, J.: Measured soil organic matter fractions can be related to pools in the RothC model, Eur. J. Soil Sci., 58, 658-667, https://doi.org/10.1111/j.1365-2389.2006.00855.x, 2007. 